\title{
Report on the Polycystididae (Rhabdocoela, Kalyptorhynchia) from Australia, with the description of twelve new species and six new genera
}

\author{
Wim R. Willems*, Ernest R. Schockaert \& Tom J. Artois \\ Research Group Biodiversity, Phylogeny and Population Studies, Centre for Environmental Sciences, Department of SBG, \\ Hasselt University, Campus Diepenbeek, Agoralaan Building D, B-3590, Diepenbeek, Belgium \\ (*Author for correspondence: Tel.: +32-11268383; Fax: +32-11268301; E-mail: wim.willems@uhasselt.be)
}

Received 26 August 2005; in revised form 19 January 2006; accepted 21 January 2006

Key words: systematics, taxonomy, biodiversity, 'Turbellaria', Kalyptorhynchia, Polycystididae

\begin{abstract}
Twelve new species of Polycystididae Graff, 1905 are described from the Australian east coast. Nine of them could not be placed in any of the existing genera, and therefore six new genera are erected. Alchoides n. gen. differs from all other polycystidid genera by the presence of a bundle of glands that opens into the distal part of the male atrium (accessory vesicle type V). Two species are included in the genus, $A$. alchoides n. sp. and A. dittmannae n. sp., which differ from each other in the shape of the stylet. Ametochus gehrkei n. gen n. sp. can be distinguished from other polycystidids by the presence of a prostate vesicle type III associated with a prostate stylet type III, combined with the presence of an accessory stylet type III, while a prostate stylet type II is lacking. Typical for Arrawarria inexpectata n. gen n. sp. is the combined presence of an armed cirrus with a prostate vesicle type II connected to a prostate stylet type II. Two species are assigned to the new genus Duplexostylus n. gen.: D. rowei $\mathrm{n}$. sp. and D. winsori n. sp. These two species have two unique features: a prostate vesicle type IV directly connected to a prostate stylet type III and an asymmetrical septum that surrounds the proximal part of the male atrium. They can be distinguished from each other by differences in the detailed construction of their stylets. Two new species are placed in the new genus Stradorhynchus n. gen.: S. caecus n. sp. and S. terminalis n. sp. They have unpaired gonads and a prostate vesicle type IV connected to a prostate stylet type IV, which combination of characters makes them unique within the Polycystididae. The two species differ from each other in the shape and size of the stylet. Triaustrorhynchus armatus n. gen., n. sp. is the first species of the Polycystididae to have three types of stylet in the male atrium: a prostate stylet type II, a prostate stylet type III and an accessory stylet type III. Three new species could be placed in existing genera: Cincturorhynchus monaculeus n. sp., Paraustrorhynchus caligatus n. sp. and Polycystis australis n. sp. All three differ from their congeners in the form and dimensions of their stylets. All newly described species are discussed, giving their similarities and differences with resembling species. Austrorhynchus hawaiiensis Karling, 1977 is reported for the first time in Australia, and the Australian population is compared with populations from other regions. The presence of Gyratrix hermaphroditus Ehrenberg, 1831, one new species of Paulodora Marcus, 1948 and a new genus of Typhlopolycystidinae Evdonin, 1977 is mentioned.
\end{abstract}

\section{Introduction}

The only kalyptorhynch species ever reported from Australia is the cosmopolitan species Gyratrix hermaphroditus Ehrenberg, 1831 (see
Curini-Galetti \& Puccinelli, 1990, 1998). This species, however, is now considered a complex of numerous species, and also in Australia several cryptic species were recognised by Curini-Galetti \& Puccinelli $(1990,1998)$. In total 108 (unidentified 
or undescribed) species of 'Turbellaria' were reported from northeastern Australia (North Queensland) in an ecological study by Dittmann (1991), the Kalyptorhynchia being the most species-rich taxon with 39 species. This fact shows how poorly known are the marine microturbellarian fauna of this large continent (for an overview, see Willems et al., 2004, 2005), although they constitute a very important group from an ecological point of view.

In this contribution, we report on 13 species of polycystidid kalyptorhynchs of which sufficient material was collected during several stays on the east Australian coast: around Townsville, on North Stradbroke Island, around Sydney and between Byron Bay and Coffs Harbour. Only one species (Austrorhynchus hawaiiensis Karling, 1977) is already known to science. The other 12 species are new to science, and some of them have such an aberrant anatomy that they could not be placed in any existing genera. This necessitated the erection of six new genera.

Apart from the species discussed, we also found G. hermaphroditus in almost every visited location. We will not further discuss this well-known species. Two more species, one belonging to the taxon Paulodora Marcus, 1948, the other to the taxon Typhlopolycystidinae Evdonin, 1977, will be treated in future monographic contributions on the respective taxa.

\section{Material and methods}

Specimens for this study were collected during three expeditions: the first in August-September 1996 by Tom Artois and Ernest Schockaert (ES), the second by ES in September-November 1997 and the third by ES in July-August 2003. Additional material and drawings were kindly provided by Dr Sabine Dittmann (Flinders University, Adelaide, Australia).

The animals were extracted from the sediment or from algae using the $\mathrm{MgCl}_{2}$-decantation method (see Schockaert, 1996), studied alive and wholemounted with lactophenol. Additional specimens were fixed in marine Bouin's solution, embedded in paraffin, serially sectioned (4 $\mu \mathrm{m}$ sections) and stained with Heidenhain's iron haematoxylin, using eosin as a counterstain.
Camera lucida drawings and photographs of hard parts were made using Nomarski microscopy. Drawings without a scale are freehand. Measurements of hard parts and body length are taken axially (i.e. with a curvimeter along the median axis of the structure), on whole mounts, unless indicated otherwise. If more than one specimen could be measured, the minimum and maximum value is given, followed by the average $(m)$ and the total number of measurements $(n)$. The number of measurements can deviate from the total number of available specimens, because some of the specimens are in a condition that does not allow the measurement of the respective structure. The position of the gonopore and organs, and the measurements of the proboscis and the pharynx are expressed in percentages of the total body length (distance from the anterior tip of the body).

Terminology of the male and female system is based on Artois \& Schockaert (2003, 2005).

Voucher specimens of A. hawaiiensis from Hawaii were loaned from the collections of the Swedish Museum of Natural History in Stockholm (SMNH).

The type material will be deposited in the collections of Hasselt University (the former Limburgs Universitair Centrum), Diepenbeek, Belgium.

\section{Taxonomical account}

As the taxonomy of the Polycystididae Graff, 1905 is rather outdated (most recent review is by Evdonin, 1977) and badly in need of revision, we decided not to organise the species following any taxonomical order. Instead, the genera are arranged alphabetically.

Alchoides alchoides n. gen., n. sp. (Figs 1, 6a) Synonymy: Alcha sp. in Watson (2001)

Distribution: North Stradbroke Island (Queensland), Adams Beach, coarse sand from a sand flat with crab-holes, 16 Sept. 1996 (type locality); same locality, Dunwich, on sand flat with crab-holes in the mid-eulittoral, in front of the marine station, 12 Aug. 1996.

Material examined: several specimens studied alive; three whole mounts (one designated 


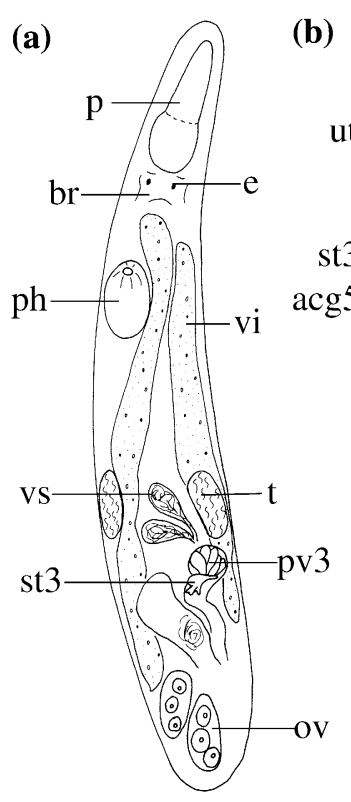

(b) $\quad \mid \cdots \cdots$ vi (c)

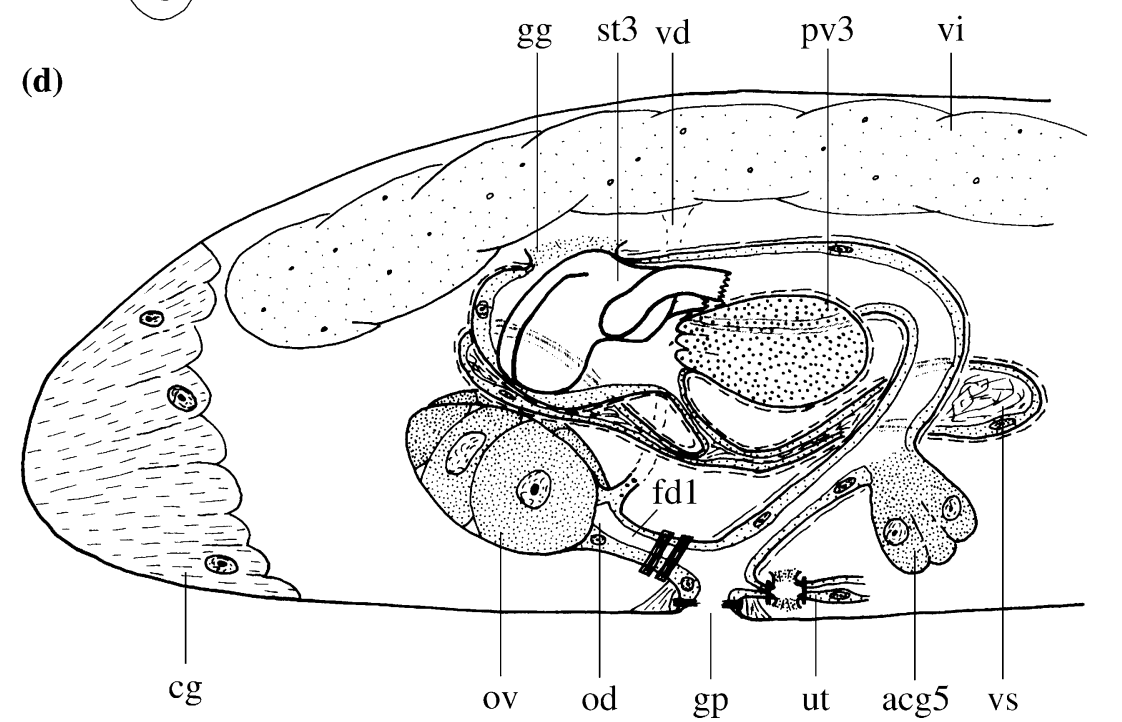

Figure 1. Alchoides alchoides n. gen., n. sp. (a) Habitus of a live animal. (b) Caudal body end with the atrial organs (from a live specimen). (c) Prostate stylet type III (from the holotype). (d) Reconstruction of the atrial organs from the right side. Abbreviations used in figures: acg1, accessory glands type I; acg3, accessory vesicle type III; acg5, accessory glands type V; ast3, accessory stylet type III; b, female bursa; br, brain; bs, bursal stalk; cg, caudal glands; de, ejaculatory duct; e, eye; fd 1, female duct type I; fg, female glands; ga, common genital atrium; gg, glands; gp, gonopore; m, mouth; ma, male atrium; mb, muscle bulb; mbu, male bursa; od, oviduct; ov, ovary; p, proboscis; ph, pharynx; pv1, prostate vesicle type I; pv2, prostate vesicle type II; pv3, prostate vesicle type III; pv4, prostate vesicle type IV; rs, seminal receptacle; s, septum; st1, prostate stylet type I; st2, prostate stylet type II; st3, prostate stylet type III; st4, prostate stylet type IV; t, testis; ut, uterus; vd, vitelloduct; vi, vitellarium; vs, seminal vesicle.

holotype: UH no. 318; the others paratypes: $\mathrm{UH}$ nos 319-320); one sagittally sectioned specimen (paratype: UH no. 321).

Etymology: the name refers to the overall resemblance of this species with Alcha evelinae Marcus, 1949.

\section{Description}

The animals are colourless, $1 \mathrm{~mm}$ long and have two eyes. The epidermis is syncytial, with several lobate nuclei. It is ca. $1 \mu \mathrm{m}$ thick, with cilia of $2 \mu \mathrm{m}$ long and a $0.5 \mu \mathrm{m}$-thick basal membrane. 
The rhabdites are mainly situated in the caudal part of the body and are ca. $1 / 3$ of the epithelium height long.

The proboscis (Fig. 1a: p) is about $20 \%$ of the body length long. Because of the rather poor quality of the sectioned animal, its construction could not be examined in detail.

The pharynx (Fig. 1a: ph) is rather small, with a diameter of only $1 / 10$ of the total body length. There are three types of pharyngeal glands: two basophilic and one eosinophilic. The prepharyngeal cavity is lined with a membranous, anucleated epithelium, which forms a ring of pseudociliation halfway along the cavity. It is surrounded by an external longitudinal and an internal circular muscle layer. The circular layer forms one sphincter at the level of the ring of pseudociliation and another one around the mouth. It is absent in the most proximal third of the cavity.

The gonads are paired. The testes are straddle the second and the last thirds of the body (Fig. 1a-b: t). The ovaries are in the caudal body end (Fig. 1a-b: ov), ovoid with the oocytes in a row. The vitellaria (Fig. 1a-b: vi) are situated dorsally and extend at both sides of the body. The common genital pore (Fig. 1b, d: gp) is at ca. $80 \%$ and can be closed by a sphincter. The short common genital atrium is lined with a high epithelium and surrounded by longitudinal muscles.

The long male atrium (Fig. 1b: ma) is narrow and lined with a high, nucleated epithelium. It is surrounded by a weak longitudinal muscle layer. It leaves the common atrium dorsally and bends caudally at about its midpoint. Proximally it widens to a broad space in which a prostate stylet type III is situated. This space is lined with a low nucleated epithelium and surrounded by circular muscles. The stylet (Figs 1a-b, d: st, c, 6a) is a very complex, plate-like structure. This plate is folded lengthways, with the two halves lying beside each other. One of the halves is $34-38 \mu \mathrm{m}$ long $(m=36 \mu \mathrm{m} ; n=3)$ and $28 \mu \mathrm{m}$ wide (difficult to measure in some individuals); the other half is $21-$ $29 \mu \mathrm{m}$ long $(m=26 \mu \mathrm{m} ; n=3)$ and $12-15 \mu \mathrm{m}$ broad ( $m=13 \mu \mathrm{m} ; n=3)$. In between both plates there is a ca. $20 \mu \mathrm{m}$ long arm, which, in some specimens, is double-folded distally. Its distal rim is provided with large teeth. The stylet is associated with a prostate vesicle type III (Fig. 1ab, d: pv3), which contains a coarse-grained basophilic secretion. It is surrounded by a circular muscle layer. In addition to the prostate vesicle, there are two accessory glandular organs. One consists of some diffuse eosinophilic glands that enter the male atrium dorsally near to the stylet (Fig. 1d: gg). The second (Fig. 1a-b, d: acg5; accessory glands type $\mathrm{V}$, terminology discussed in the 'Discussion' on Alchoides; see further) produces a fine-grained basophilic secretion and opens in the distal part of the male atrium. The paired seminal vesicles (Fig. 1a-b, d: vs) are surrounded by a spirally running, almost circular muscle coat. The vasa deferentia join each other ventrally from the prostate vesicle to form the ejaculatory duct. The ejaculatory duct is surrounded by circular muscles and enters the male atrium next to the glandular vesicle.

The female duct type I (Fig. 1d: fd1) is rather short and lined with a low nucleated epithelium. It is surrounded by a very weak circular muscle layer, which forms a weak sphincter distally. The vitelloducts enter the oviducts dorsally. Female glands as in Alchoides dittmannae (see further) could not be seen, probably because of the poor quality of the sections.

The uterus (Fig. 1d: ut) is of the normal polycystidid type.

\section{Diagnosis}

Alchoides n. gen.: Polycystididae with eyes and with paired gonads and paired seminal vesicles. Only one hard part in the male system: a prostate stylet type III, associated with a prostate vesicle type III. Prostate vesicle type III surrounded by a weak circular muscle layer. The accessory vesicle type $\mathrm{V}$ enters the distal part of the male atrium. Female system very simple, consisting of a female duct type I proximally splitting into the two oviducts. Type species: A. alchoides n. sp.

Alchoides alchoides n. sp.: species of Alchoides with a bundle of glands entering the proximal part of the male atrium. Prostate stylet type III ca. $36 \mu \mathrm{m}$ long and ca. $40 \mu \mathrm{m}$ wide, a complex platelike structure, lengthways folded into two halves, with a distally toothed arm in between. 


\section{Discussion}

See the discussion on $A$. dittmannae n. sp.

Alchoides dittmannae n. gen., n. sp. (Figs 2, 6b)

Distribution: Broken Head (New South Wales), coarse sand between rocks, south of the abutment pier, 27 Oct. 1997 (type locality).

Material examined: several specimens studied alive; four whole mounts (one designated holotype: UH no. 322; the others paratypes: UH nos 323-325); two animals sagittally sectioned (paratypes: UH nos 326-327).

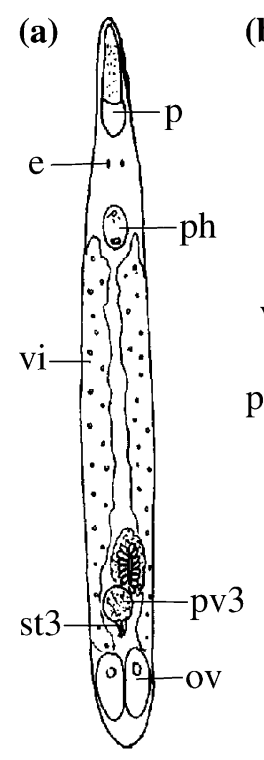

(b)

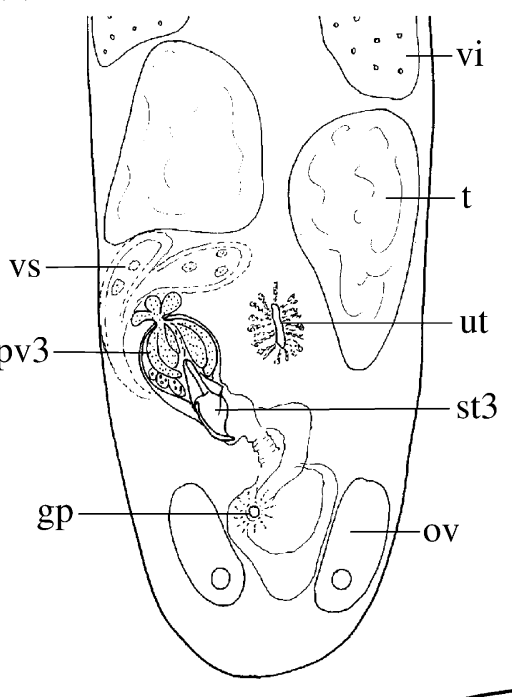

(c)

The animals are $0.5-0.8 \mathrm{~mm}$ long, colourless and have two eyes. The epidermis is syncytial and contains lobate nuclei. It is $1 \mu \mathrm{m}$ thick with cilia $2 \mu \mathrm{m}$ long. The basal membrane is $1 \mu \mathrm{m}$ thick. Rhabdites are sparsely distributed over the whole body surface and are about half the epithelium height long.

Dittmann (Flinders University, Adelaide, Australia).

\section{Description}

(d)

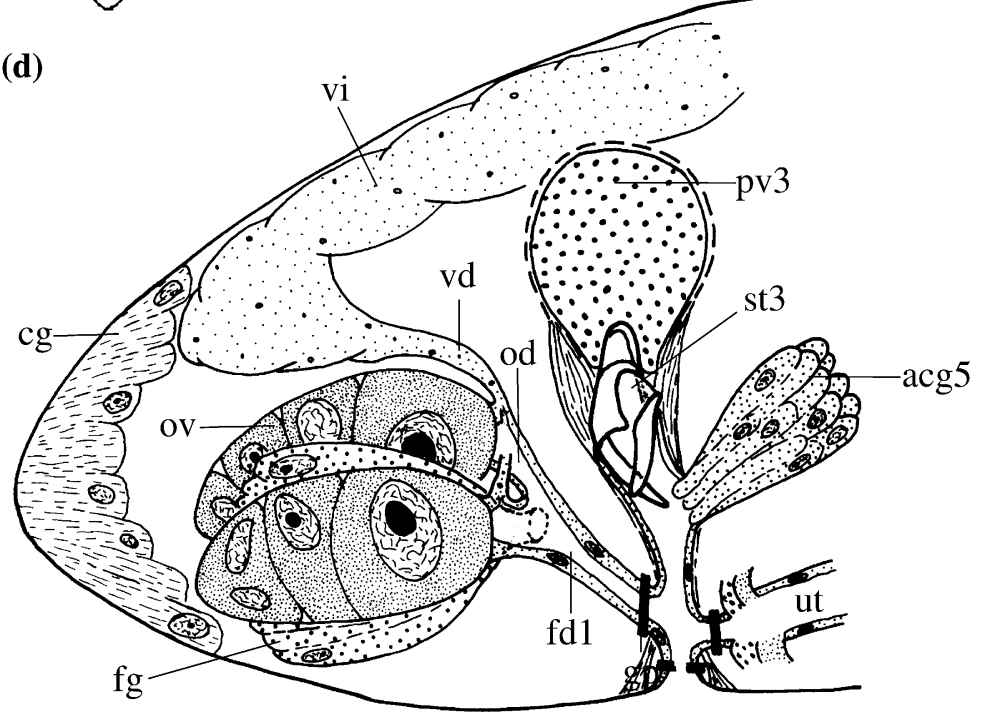

Figure 2. Alchoides dittmannae n. gen., n. sp. (a) Habitus of a live animal. (b) Caudal body end with the atrial organs (from a live specimen). (c) Prostate stylet type III (from the holotype). (d) Reconstruction of the atrial organs from the right side. 
The proboscis (Fig. 2a: p) is ca. $15 \%$ of the total body length long. The epithelium of the proboscis sheath contains four nuclei. There are no nuclei in the contact zone between cone and sheath epithelium. There is one pair of ventral integument retractors. The number of proboscis retractors could not be determined with certainty, but there are probably four pairs.

The construction of the pharynx (Fig. 2a: ph) is identical to that of $A$. alchoides. It is, however, somewhat smaller, with a diameter of only $1 / 15$ of the body length.

The construction of the genital system (Fig. 2b, d) resembles that of $A$. alchoides. The main differences with this species are found in the shape of the prostate stylet type III (Figs 2a-b, d: st3, c, 6b). It also is a double-folded plate, but is less complex. It lacks the toothed arm, and distally ends in two blunt points. In total, it is $32-36 \mu \mathrm{m}$ long $(m=34 \mu \mathrm{m} ; n=3)$ and $9-11 \mu \mathrm{m}$ broad $(m=10 \mu \mathrm{m} ; n=3)$. At each side, the plate has two small linguiform projections that are orientated towards each other. The accessory glands type $\mathrm{V}$ (Fig. 2d: acg5) are much larger than in A. alchoides and very obvious even in live animals. The proximal bundle of accessory glands that exists in $A$. alchoides is lacking. The paired seminal vesicles (Fig. 2b: vs), easily distinguishable in the live animals, could not be seen in the sectioned material. As a consequence, the exact location where the ejaculatory duct enters the male atrium could not be determined. It is probably situated at the distal tip of the stylet (observations on live material).

The female system (Fig. 2d) is identical to that of $A$. alchoides, except for the presence of a large bundle of female glands (Fig. 2d: fg), which opens into the female system at the bifurcation of the female duct.

\section{Diagnosis}

A. dittmannae n. sp.: species of Alchoides without a bundle of glands entering the proximal part of the male atrium. Prostate stylet type III ca. $34 \mu \mathrm{m}$ long and ca. $10 \mu \mathrm{m}$ wide, consisting only of a lengthways-folded plate, with the two halves distally ending in blunt points. Each plate with a small linguiform projection which points to the other half of the stylet. Female glands present.

\section{Discussion}

The presence of only a prostate vesicle type III associated with a prostate stylet type III, without any other glandular organ and stylet in the male system, is rather uncommon within the Polycystididae. Apart from the species of Alchoides it is only found in A. evelinae Marcus, 1949, Rogneda minuta Uljanin, 1870 and Sabulirhynchus axi Artois \& Schockaert, 2000. The species of Alchoides clearly differ from these other taxa, in that they have a large bundle of glands opening in the distal part of the male atrium, a feature unique within the Polycystididae. Following the same terminology as Artois \& Schockaert, (2003) we will call this glandular bundle of glands the accessory vesicle type V. Moreover, in both species of Alchoides, the prostate vesicle type III is surrounded by a weak but clearly visible circular muscle layer, a feature only found in one other polycystidid taxon: Galapagorhynchus Artois \& Schockaert, 1999, to which they are clearly not closely related. An important difference between A. evelinae and the three other taxa mentioned is the presence of insemination ducts (terminology of Artois \& Schockaert, 2005) in this taxon, which are clearly lacking in the species of Alchoides.

The organisation of the female system is extremely simple in the two species of Alchoides and is identical to the situation in many other polycystidid taxa, e.g. Rogneda Uljanin, 1870 and Ametochus nov. gen (see further). Whether terminal female glands are really lacking in $A$. alchoides is doubtful, as it is also possible that we did not find them because of the rather poor quality of the sections. Their presence/absence in this species should be checked on new material.

Both species of Alchoides can easily be identified by the construction and dimensions of the stylet. Moreover, the bundle of glands that enters the proximal part of the male atrium in Alchoides alchoides, is absent in A. dittmannae. Because this bundle is not found in any of the other Polycystididae it is probably an autapomorphy of A. alchoides.

Ametochus gehrkei n. gen., n. sp. (Figs 3, 6c-d) Distribution: North Stradbroke Island (Queensland), Adams Beach, coarse sand from a eulittoral sand flat with crab-holes, 16 Sept. 1996 
(type locality); same locality, Dunwich, sand flats with coarse or fine crab-holes in mid-eulittoral, in front of the marine station, 12, 13 and 20 Aug. 1996. Sydney (New South Wales), Vaucluse Bay \& Rose Bay, beach with fine sand and crab-holes, mid-eulittoral, 10 Oct. 1997.
Material examined: several specimens studied alive; thirteen whole mounts, ten of which are from the type locality (one designated holotype: UH no. 328); several animals serially sectioned.

Etymology: ametochos (Gr.): neutral, as the genus has no really eye-catching features; the (a)
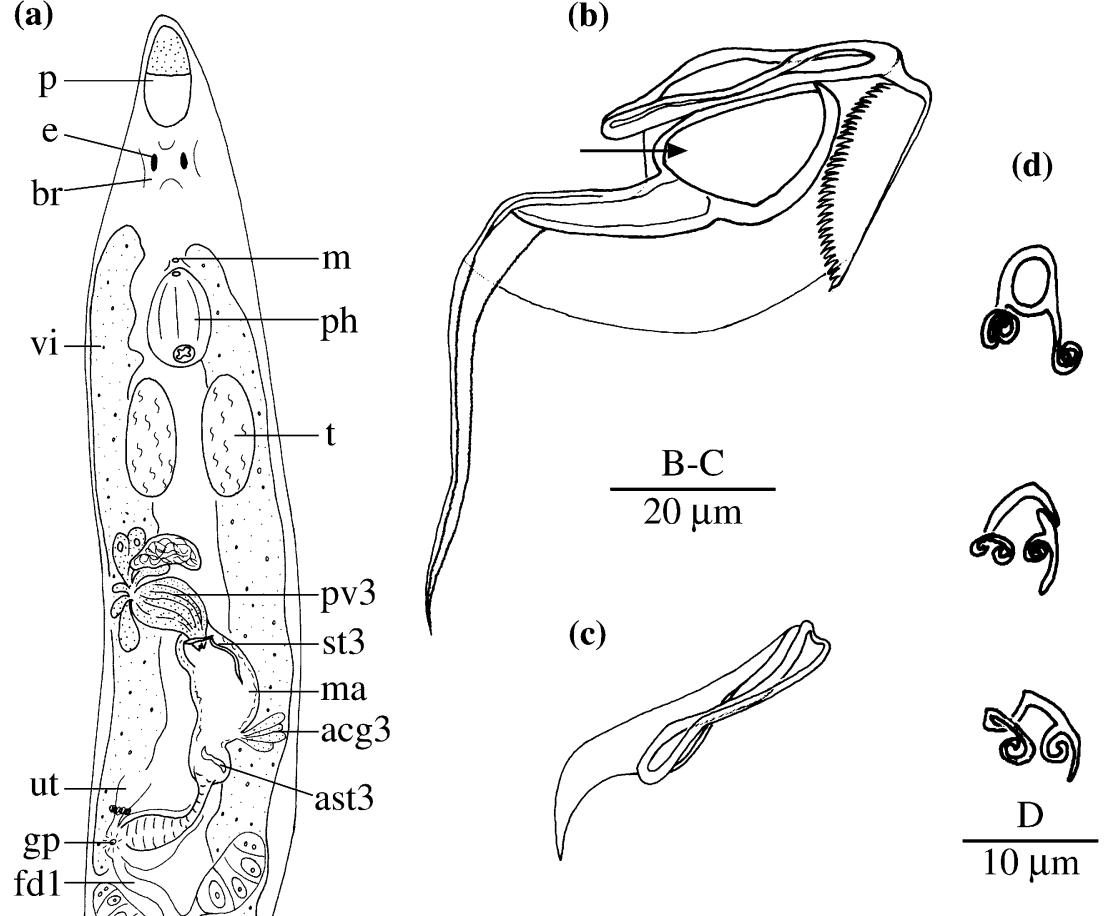

(b)

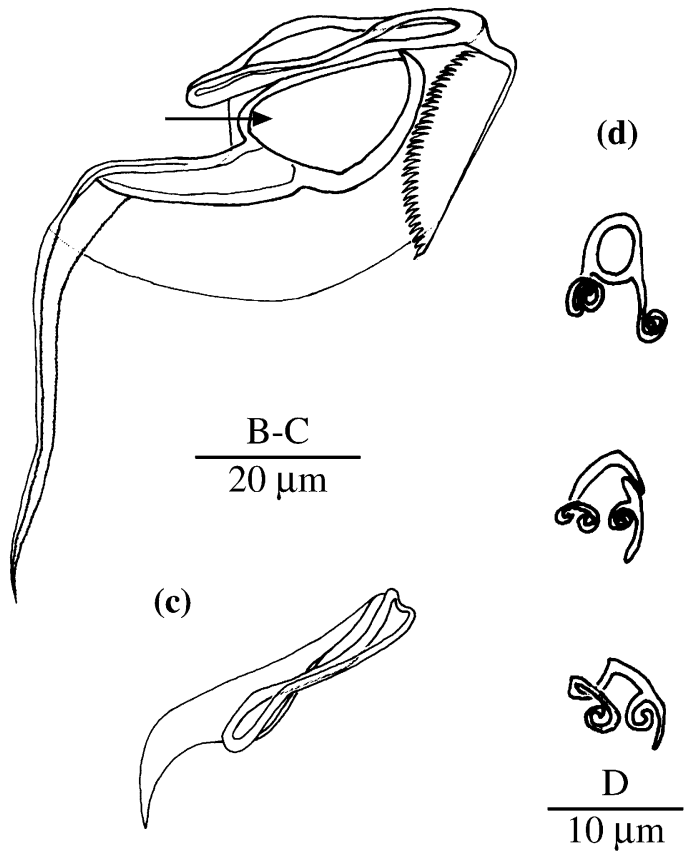

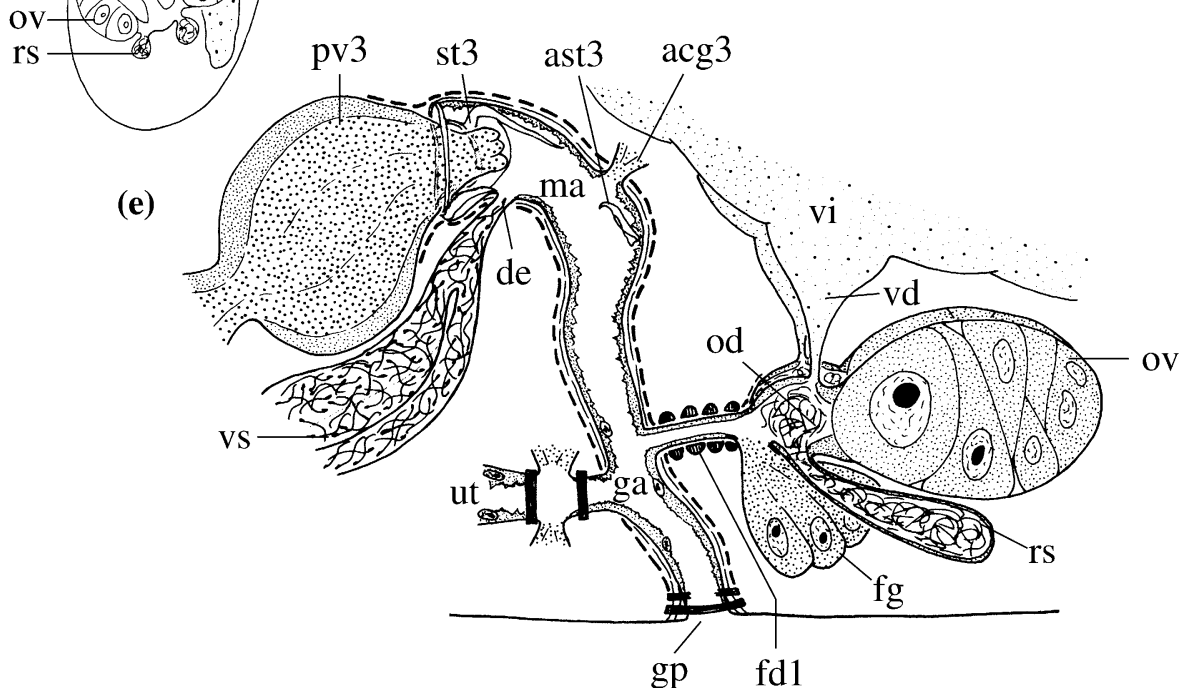

Figure 3. Ametochus gehrkei n. gen., n. sp. (a) General organisation (from a live specimen). (b) Prostate stylet type III (arrow indicates the 'window'; from the holotype). (c) Accessory stylet type III (from the holotype). (d) Three transverse sections through the accessory stylet type III (top: distally, bottom: proximally). (e) Reconstruction of the atrial organs from the left side. 
species is dedicated to John Gehrke, the janitor of the marine station on Stradbroke Island.

\section{Description}

The animals are colourless to pale yellow, $1 \mathrm{~mm}$ long, with two eyes. The epidermis is syncytial. It is $4 \mu \mathrm{m}$ thick with cilia $2 \mu \mathrm{m}$ long. The basal membrane is ca. $1 \mu \mathrm{m}$ thick. The rhabdites are less than half the epithelium height long, and are absent at the level of the proboscis. Caudal glands are well developed.

The proboscis (Fig. 3a: p) is small, about $1 / 8$ of the body length, and is situated in the first body half. The epithelium of the proboscis sheath is high, without nuclei. Nuclei are also lacking at the junction of the sheath and cone epithelia. The sheath is surrounded by an inner circular and an outer longitudinal muscle coat. There are four pairs of proboscis retractors and a single pair of ventral integument retractors.

The pharynx (Fig. 3a: ph) is situated in the first body half and slightly inclined forwards. Four teeth are present around the proximal pharyngeal opening. The prepharyngeal cavity is lined with a low anucleated epithelium. Approximately in the middle of the prepharyngeal cavity, the epithelium forms a ring of pseudociliation. The cavity is surrounded by an internal circular and an external longitudinal muscle layer. The pharyngeal lumen has a relatively high epithelium, which contains four nuclei arranged in pairs at different heights. There are 24 internal longitudinal muscles. There are three types of pharyngeal glands, which open in the distal part of the pharyngeal lumen.

The gonads are paired. The testes (Fig. 3a: t) are small and lie at both sides of the body slightly behind the pharynx. The ovoid ovaries (Fig. 3a, e: ov) are situated caudally. The long vitellaria (Fig. 3a, e: vi) extend dorsally at both sides of the body. The common genital pore (Fig. 3a, e: gp) lies at $75 \%$ of the body length and can be closed by a sphincter. The common genital atrium (Fig. 3e: ga) is lined with a high epithelium, containing a few nuclei. The atrium is surrounded by external circular and internal longitudinal muscles. Both layers continue along the male genital atrium, which is lined with a pseudociliated epithelium.

The prostate stylet type III (Figs 3a: st3, b, 6c) is situated in the proximal part of the male atrium.
It consists of a ring, which is $26-40 \mu \mathrm{m}$ long $(m=33 \mu \mathrm{m} ; n=12)$ and $8-17 \mu \mathrm{m}$ wide $(m=10 \mu \mathrm{m}$; $n=12$ ). Part of this ring carries a large and thin plate, which is folded at one side. The edge of the plate that is most near to the fold is clearly toothed; the proximal edge is thin and smooth. The fold itself is thickened. Also, the opposite edge is much thicker and ends in a 57-68 $\mu \mathrm{m}$-long serrate spine $(m=59 \mu \mathrm{m} ; n=12)$. At about $1 / 3$ of its length the spine makes a $90^{\circ}$ twist. Where the plate attaches to the ring, it shows a hole with sturdy edges ('window', arrow in Fig. 3b), which is about 9-14 $\mu \mathrm{m}(m=12 \mu \mathrm{m} ; n=10)$ diameter. The plate is about $9-19 \mu \mathrm{m}$ high $(m=14 \mu \mathrm{m} ; n=10)$ and $33-$ $41 \mu \mathrm{m}$ broad $(m=38 \mu \mathrm{m} ; n=10)$ at one side of the fold, $6-11 \mu \mathrm{m}$ broad $(m=8 \mu \mathrm{m} ; n=10)$ at the other. A prostate vesicle type III (Fig. 3a, e: pv3) enters the male atrium proximally. The glands bulge out deeply into the male atrium through the proximal ring of the stylet. Two sorts of secretion are present: one coarse-grained eosinophilic and one fine-grained basophilic. Only the distal part of the vesicle is surrounded by a layer of circular muscles. These muscles are continuous with the circular muscles of the male atrium. The elongated and fusiform seminal vesicles (Fig. 3e: vs) are situated ventrally from the glandular vesicle. Distally they fuse to form the ejaculatory duct. It was not possible to determine the exact place where the ejaculatory duct opens into the male system, but it is probably situated near the proximal ring of the stylet. More distally in the male atrium there is an accessory stylet type III (Figs 3a, e: ast3, c-d, 6d). This accessory stylet is a hollow spine of $34-55 \mu \mathrm{m}$ long $(m=44 \mu \mathrm{m} ; n=12)$ with a hook-shaped distal end. It is associated with some diffuse accessory glands, which produce a basophilic secretion (= accessory vesicle type III; Fig. 3a, e: acg3).

The female duct type I (Fig. 3a, e: fd1) enters the common atrium caudally. It is lined with a low, anucleated epithelium and surrounded by a strong circular muscle layer. The oviducts (Fig. 3e: od) are swollen and filled with sperm, functioning as seminal receptacles (after copulation). They are distally surrounded by circular muscles. The ventral wall of each oviduct has a large bulge, which is filled with sperm (seminal receptacle; Fig. 3a, e: rs). The vitelloducts (Fig. 3e: vd) enter the oviduct dorsally. At the bifurcation of the female duct into the oviducts, there is a large bundle of glands (Fig. 3e: fg). 
The uterus (Fig. 3e: ut) is of the normal polycystidid type.

\section{Diagnosis}

Ametochus n. gen.: Polycystididae with eyes and with a proboscis with four retractors and one pair of (ventral) integument retractors. Gonads paired. Male system with two hard parts: a prostate stylet type III, associated with a prostate vesicle type III, and an accessory stylet type III, associated with an accessory vesicle type III. Female duct of type I with a thick circular muscle layer. Oviducts function as seminal receptacles after copulation. Each oviduct with a large ventral bulge that functions as a seminal receptacle. Female glands present. Type and only species: A. gehrkei n. sp.

A. gehrkei n. sp.: species of Ametochus with a prostate stylet type III consisting of a ring through which the prostate glands enter the male atrium. This ring is ca. $33 \mu \mathrm{m}$ long and ca. $10 \mu \mathrm{m}$ wide. Accessory stylet type III a hollow spine, ca. $44 \mu \mathrm{m}$ long, with a hook-shaped distal end. One side of the ring carries a perpendicular plate, which shows a large hole underneath the proximal ring. At one side this plate narrows into a long, narrow, pointyending spine, at the other side it shows a fold with a serrated edge.

\section{Discussion}

A prostate vesicle type III in close association with a prostate stylet type III is a rather common combination within the Polycystididae, being found in a wide variety of taxa. However, the occurrence of both these structures together with an accessory stylet type III is almost unique within the Polycystididae, and is only found in Triaustrorhynchus armatus nov. gen. nov. sp. (described in this paper, see below). However, T. armatus differs clearly from $A$. gehrkei in that it also has a prostate stylet type II connected to a prostate vesicle type II, which is lacking in $A$. gehrkei. The occurrence of an accessory stylet type III is rather uncommon within the Polycystididae anyhow. It is only found in Porrocystis assimilis (Levinsen, 1879) Reisinger, 1924 and species of Austrorhynchus Karling, 1952, where it occurs in combination with a prostate stylet type II attached to a prostate vesicle type
II. In none of these species is it combined with an accessory vesicle type III, as is the case in $A$. gehrkei. The unique combination of all features mentioned marks Ametochus as a new genus.

The female system is very much like that of Alchoides. The seminal receptacles that are connected to the oviducts are, however, almost unique within the Polycystididae. A comparable situation is only found in Paulodora subcontorta (Schockaert, 1982) Artois \& Schockaert, 1998 and some yet undescribed related species of Paulodora. This is, however, most probably a parallelism, as the two genera do not share any other typical characteristics.

Arrawarria inexpectata n. gen., n. sp. (Figs 4, 6e) Synonymy: Arrawaria n. gen. in Littlewood et al. (1999)

Arrawaria in Joffe \& Kornakova (2001)

Arrawaria sp. in Littlewood \& Olson (2001)

'arrawarria inexpectata' in Willems et al. (2006)

Distribution: Arrawarra (New South Wales), small shell-shaped brown algae from a tidal pool in the mid-eulittoral, 28 Aug. 1996 (type locality); same locality, various algae from several tidal pools near the marine station, 27 and 28 Aug. 1996 and 1 Nov. 1997. Sydney (New South Wales, Australia), various algae from Bondi Beach, 6 Oct. 1996.

Material examined: several specimens studied alive; ten whole mounts, one of them designated holotype (UH no. 329), two others paratype (UH nos 330-331); a total of ten animals serially sectioned.

Etymology: genus name derived from the type locality (Arrawarra); the species epithet refers to the unexpected combination of an armed cirrus with a prostate vesicle type II connected to a prostate stylet type II.

\section{Description}

Colourless animals of about $0.8-1.2 \mathrm{~mm}$ long, with two eyes.

The epidermis is syncytial, ca. $4 \mu \mathrm{m}$ thick, with cilia of $3 \mu \mathrm{m}$ long and a thick basal membrane. Rhabdites are few, spindle-shaped and about half the epithelium height long. Caudal glands are well developed. 


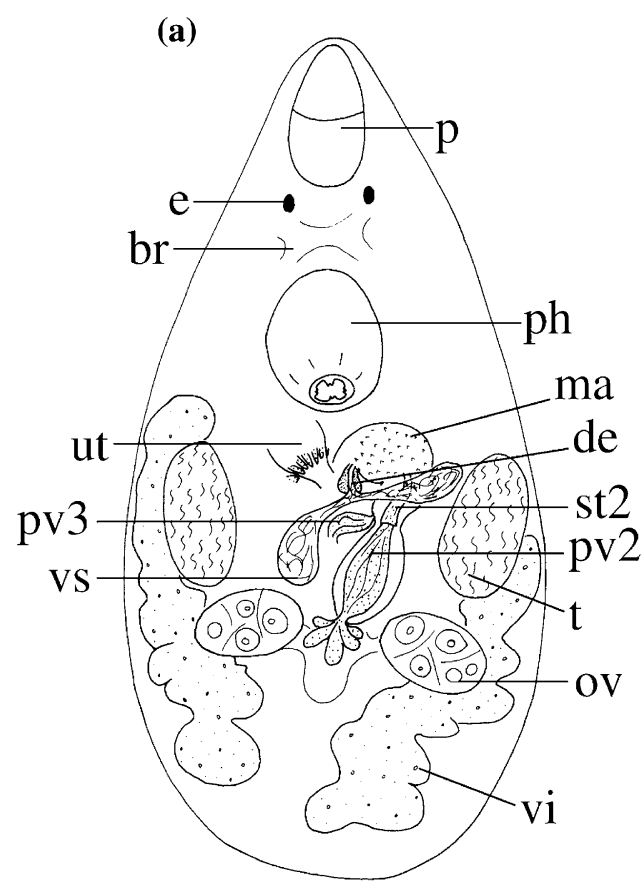

(b)

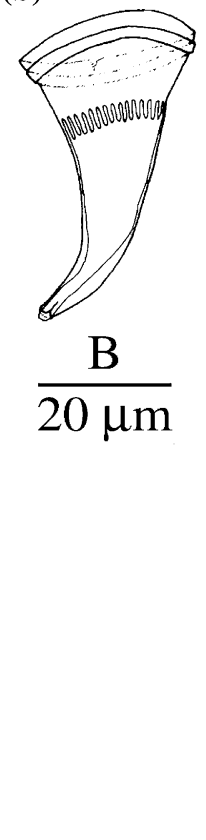

(c)

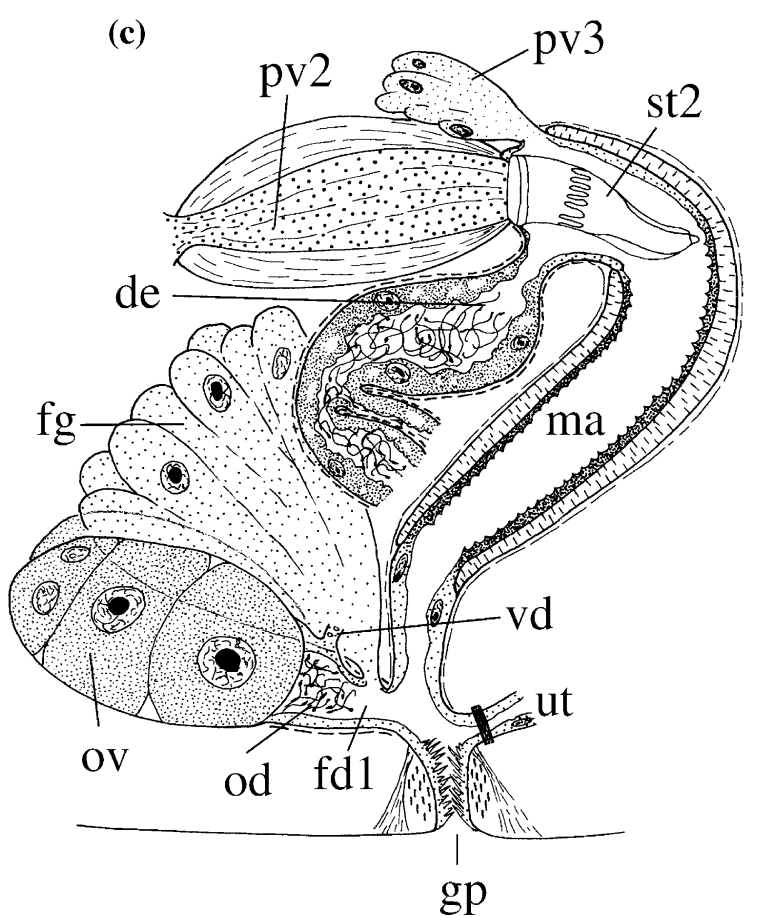

Figure 4. Arrawarria inexpectata n. gen., n. sp. (a) General organisation (from a live specimen). (b) Prostate stylet type II (from the holotype). (c) Reconstruction of the atrial organs from the right side.

The proboscis (Fig. 4a: p) is about $1 / 5$ of the body length long. The proboscis sheath is lined with a high, nucleated epithelium and is surrounded by an inner circular and an outer longitudinal muscle layer. The circular layer is missing in the distal $1 / 3$ of the cavity. There are no nuclei at the contact zone between sheath and cone epithelia. There are six bundles of fixators, one ventral pair of integument retractors and four pairs of proboscis retractors.

The pharynx (Fig. 4a: ph) is in the first body half and inclined forwards. The prepharyngeal cavity is lined with a very low, anucleated epithelium, which forms a ring of pseudociliation in the middle of the cavity. The cavity is surrounded by an inner circular and an outer longitudinal muscle layer. The circular layer forms a sphincter at the mouth and at the ring of pseudociliation, but is lacking in the proximal third of the cavity. There are four hard teeth around the proximal pharyngeal opening. The number of internal longitudinal muscles in the pharynx bulb amounts to 24 . There are three kinds of pharyngeal glands that open into the distal part of the pharyngeal lumen.
The gonads are paired. The testes (Fig. 4a: t) are rather small and situated behind the pharynx at both sides of the body. The ovoid ovaries (Fig. 4a, c: ov) are situated caudally, just behind the gonopore (Fig. 4c: gp). The vitellaria extend dorsally at both sides of the body. The gonopore is at about $70 \%$. The common genital atrium is small and lined with pseudociliation. It is surrounded by an inner circular and an outer longitudinal muscle layer. The circular layer forms a thick sphincter around the gonopore.

The male atrium (Fig. 4a, c: ma) enters the common atrium dorsally. It is very long and bends caudally. The distal $1 / 4$ of the male atrium is lined with a high, nucleated epithelium and surrounded by a barely visible inner circular and an outer longitudinal muscle layer. The rest of the male atrium is lined with a pseudocuticula, forming small spines (armed cirrus). The inner muscle layer surrounding this part is very thick. Proximally a prostate vesicle of type II (Fig. 4a, c: pv2) enters the male atrium and discharges its secretion through a prostate stylet type II (Figs 4a, c: st2, $4 \mathrm{~b}, 6 \mathrm{e})$. The prostate vesicle consists of about four 
gland necks, with a coarse-grained basophilic secretion. It is surrounded by a very thick circular muscle layer, which distally becomes more spiral, even longitudinal. The outer fibres are continuous with the muscles surrounding the male atrium; the inner fibres attach to the proximal rim of the stylet. The prostate stylet type II is double-walled, slightly curved and tapers towards its distal tip. It is 50-54 $\mu \mathrm{m}$ long $(m=53 \mu \mathrm{m} ; n=9)$ and $24-29 \mu \mathrm{m}$ broad proximally ( $m=26 \mu \mathrm{m} ; n=9)$. The proximal rim of the outer stylet is thickened. The inner stylet is in the distal 2/3 of the stylet. Both vasa deferentia are very swollen and have a glandular epithelium (false seminal vesicles). They join each other ventrally from the prostate vesicle type II. The ejaculatory duct (Fig. 4a, c: de) is also very swollen (seminal vesicle) and lined with a high, glandular epithelium. It enters the male atrium proximally, near the base of the stylet. Dorsally from the prostate vesicle type II, there is a prostate vesicle type III (Fig. 4a, c: pv3), which only consists of eosinophilic glands and is not surrounded by muscles. It enters the male atrium dorsally from, and very near to, the prostate vesicle type II.

The female duct type I (Fig. 4c: fd1) enters the common genital atrium caudally. It is lined with a high, anucleated epithelium. It is very short and almost immediately splits into the two oviducts (Fig. 4c: od). These oviducts are swollen and filled with sperm, functioning as seminal receptacles. The oviducts and the common female duct are surrounded by circular muscles only. At the junction of the oviducts there is a large bundle of basophilic glands (Fig. 4c: fg). The vitelloducts (Fig. 4c: vd) enter the oviducts dorsally.

The uterus (Fig. 4c: ut) is of the normal polycystidid construction. It leaves the common genital atrium out of its frontal wall.

\section{Diagnosis}

Arrawarria n. gen.: Polycystididae with eyes. Proboscis with four pairs of retractors and one pair of ventral integument retractors. Gonads paired. Vasa deferentia forming two glandular false seminal vesicles. Ejaculatory duct forms one large, glandular seminal vesicle. With a prostate vesicle type II, connected to a prostate stylet type II. Prostate vesicle type III present. Male atrium forming an armed cirrus. Female duct extremely short. Oviducts function as seminal receptacles after copulation. Female glands present.

Arrwarria inexpectata $\mathrm{n}$. sp.: species of Arrawarria with a slightly curved prostate stylet type II, which is ca. $53 \mu \mathrm{m}$ long and tapers towards its distal tip. Inner stylet only in the distal $2 / 3$ of the stylet.

\section{Discussion}

The male system of $A$. inexpectata somewhat resembles that of species of the taxon Acrorhynchides Strand, 1928, especially that of Acrorhynchides robustus (Karling, 1931) Strand, 1928. All species of Acrorhynchides and A. inexpectata have a prostate vesicle type III entering an armed cirrus, all show a combination of two false seminal vesicles and a single 'real' seminal vesicle, and in all species the false seminal vesicles have a high and glandular epithelium. Only in A. robustus and $A$. inexpectata the seminal vesicle proper also has a high and glandular epithelium. A. inexpectata differs from the species of Acrorhynchides in that a prostate vesicle type II connected to a prostate stylet type II is also present. The combination of such a vesicle and stylet with a cirrus is unique within the Polycystididae, and warrants the placement of this new species in a genus of its own.

The female system is rather simple, and is similar to that of many other species of Polycystididae. The ovaries are ovoid, which also distinguishes $A$. inexpectata from the species of Acrorhynchides, which have globular ovaries.

Austrorhynchus hawaiiensis Karling, 1977 (Figs 5, 6f)

Synonymy: Austrorhynchus pectatus in Karling et al. (1972)

(a)

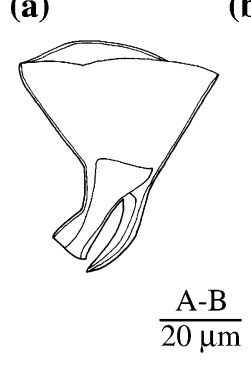

(b)

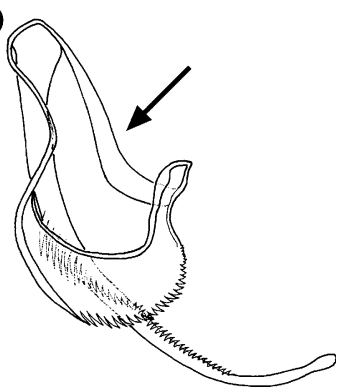

Figure 5. Austrorhynchus hawaiiensis Karling, 1977. (a) Prostate stylet type II. (b) Prostate stylet type III (arrow indicates clasp). (a, b) both from an Australian specimen) 
Distribution in Australia: North Stradbroke Island (Queensland), Dunwich, in an exposed sea grass field in front of the marine station, 12 and 13 Aug. 1996; same locality, Amity Point, in a sea grass field with some mud in the tidal zone, 13 Aug. 1996.

Further distribution: Hawaii, Oahu, (Karling et al., 1972). Zanzibar Island (Tanzania), Mbweni,
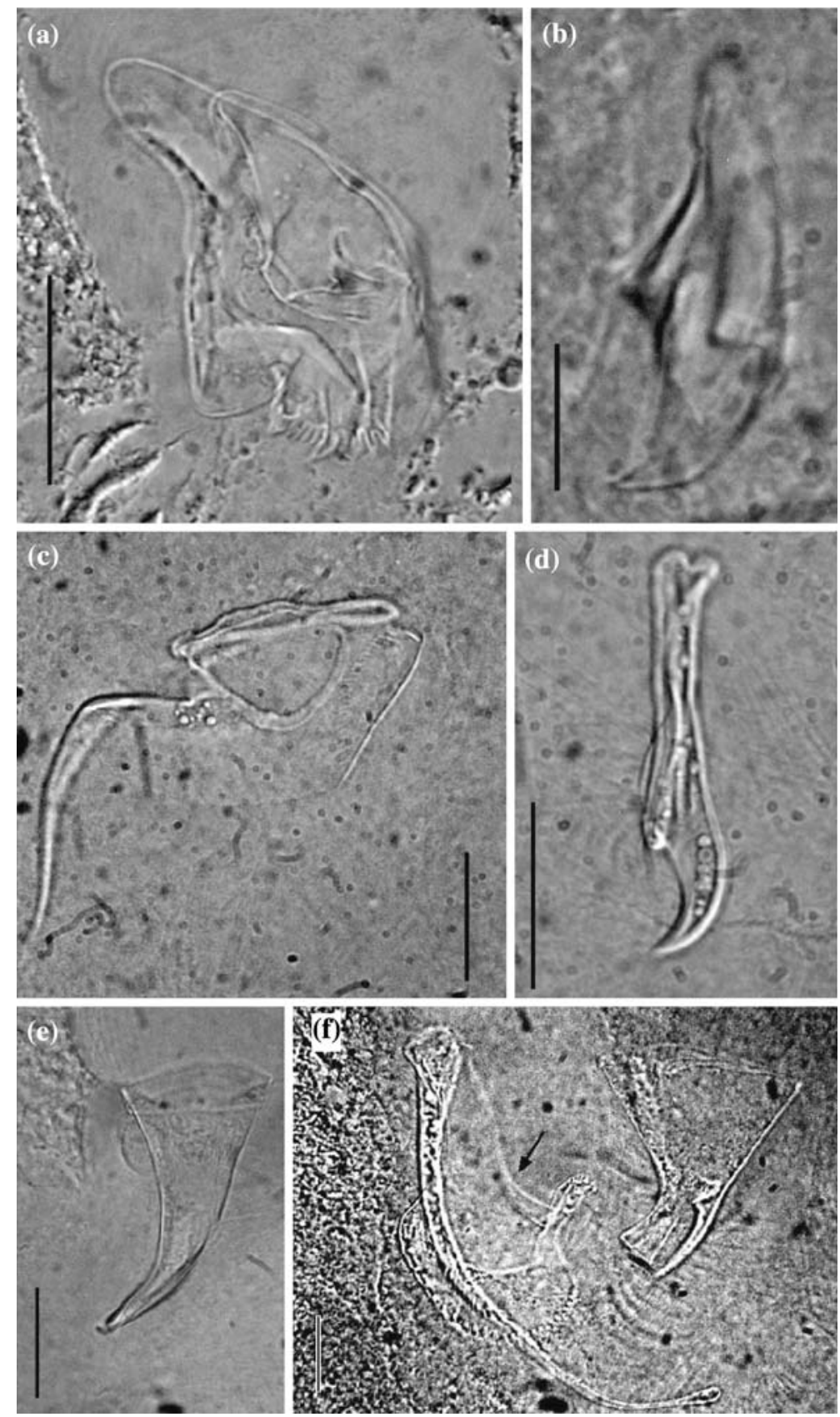

Figure 6. Alchoides alchoides n. gen., n. sp. (a) Prostate stylet type III (from the holotype). Alchoides dittmannae n. sp. (b) Prostate stylet type III (from the holotype). Ametochus gehrkei n. gen., n. sp. (c) Prostate stylet type III (from the holotype). (d) Accessory stylet type III (from the holotype). Arrawarria inexpectata n. gen., n. sp. (e) Prostate stylet type II (from the holotype). Austrorhynchus hawaiiensis Karling, 1977. (f) Prostate stylet type III (left; arrow indicates clasp) and prostate stylet type II (right). Scale bars: $20 \mu \mathrm{m}$. 
beach behind the Mbweni Ruins Hotel, north of the creek, in a little pool with sea grass (Thalassia spec?), 11 Aug. 1995; same locality, from a beach situated a bit higher, with relatively coarse sand, pebbles and silt from between sea grass (Halodule), rich in detritus, 11 Aug. 1995; same locality, in a tidal pool with broad-leafed sea grass, 17 Aug. 1995.

Material examined: two whole mounts and one sectioned specimen from Hawaii (SMNH); several animals studied alive in Zanzibar and Australia; three whole mounts from Zanzibar (coll. UH); three whole mounts and three serially sectioned specimens from Australia (coll. UH).

\section{Additional information}

As to the general shape of the hard parts of the male system, the specimens from Zanzibar, Australia and Hawaii are indistinguishable from each other. The prostate stylet type III (Figs 5b, 6f: left) is very much like that of Austrorhynchus bruneti Karling, 1977, with a pronounced style and foot connected to each other by a narrow clasp (indicated by an arrow in Figs 5b, 6f). The doublewalled prostate stylet type II of the specimens from Zanzibar is $27-31 \mu \mathrm{m}$ long $(m=29 \mu \mathrm{m} ; n=3)$. The prostate stylet type III is $62-68 \mu \mathrm{m}$ long $(m=65 \mu \mathrm{m} ; n=3)$ with a plate $24-28 \mu \mathrm{m}$ broad and 6-7 $\mu \mathrm{m}$ high $(n=2)$. The Hawaiian and Australian populations seem to have larger hard parts. Only one specimen from Australia could be measured properly. It has a $41 \mu \mathrm{m}$-long prostate stylet type II (Figs 5a, 6f: right) and a very long prostate stylet type III (106 $\mu \mathrm{m}$; Figs 5b, 6f: left). The plate of the latter stylet is $36 \mu \mathrm{m}$ broad and $13 \mu \mathrm{m}$ high. The prostate stylet type II of the Hawaiian population is $35-38 \mu \mathrm{m}$ long. The prostate stylet type III of this population is $80 \mu \mathrm{m}$ long $(n=2)$, with a plate $30-33 \mu \mathrm{m}$ broad and $7 \mu \mathrm{m}$ high $(n=2)$.

Cincturorhynchus monaculeus n. sp. (Figs 7, 10a-b)

Distribution: Arrawarra (New South Wales), large tidal pool on the southern part of the beach at the beginning of a rocky area, 27 Aug. 1996 and 27 Oct. 1997 (type locality); same locality, large algae from a tidal pool, 27 Oct. 1997; same locality, Mullaway headland, on algae from deep rock pools, 24 Jul. 2003. North Stradbroke Island
(Queensland), in sea grass from tidal pools in the mid-eulittoral in front of the marine station, 13 Aug. 1996 and 20 Oct. 1997.

Material examined: several animals studied alive and mounted, one of them designated holotype (UH no. 332); one sagittally sectioned animal from North Stradbroke Island.

Etymology: the prostate stylet type II has one spine only. Mono (Gr.): single; aculeus (Lat.): sting.

\section{Description}

Animals 1-1.5 mm long, yellowish under incident light, with two eyes.

The internal organisation is comparable to that of Cincturorhynchus karlingi Schockaert, 1982. The hook-shaped prostate stylet type II (Figs 7a, $10 \mathrm{~A}$ ) is a double-walled tube, with a very broad, annular proximal base of $31-46 \mu \mathrm{m}(m=40 \mu \mathrm{m}$; $\mathrm{n}=9)$ diameter. It is $42-57 \mu \mathrm{m}$ long $(m=49 \mu \mathrm{m}$; $n=9)$. A 36-46 $\mu \mathrm{m}$ long $(m=41 \mu \mathrm{m} ; n=9)$, hollow spine is attached to the proximal base of this stylet and runs more or less parallel to it, but it is less curved. The prostate stylet type III (Figs 7b, 10b) consists of a proximal semicircular to horseshoeshaped ring, which carries long, curved spines. The diameter of the base is difficult to measure in the different specimens, as its size is largely dependent on the degree of compression. It fluctuates between 55 and $118 \mu \mathrm{m}(m=84 \mu \mathrm{m} ; n=9)$. The spines are implanted into two different groups, one consisting of long spines (ca. $34 \mu \mathrm{m}$ ), the other of shorter ones (ca. $16 \mu \mathrm{m}$ ).

The sectioned specimen lacks a female bursa, although it was clearly visible in live animals. Probably the sectioned animal has not yet reached full female maturity. (a)

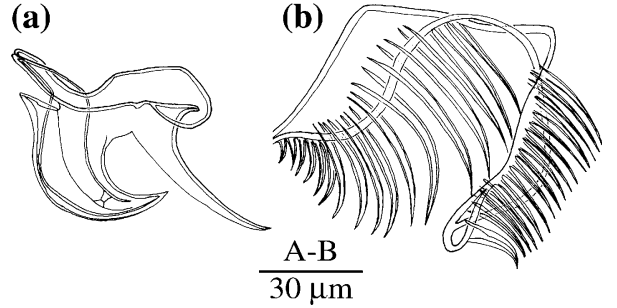

Figure 7. Cincturorhynchus monaculeus n. sp. (a) Prostate stylet type II (from the holotype). (b) Prostate stylet type III (from the holotype). 


\section{Diagnosis}

C. monaculeus n. sp.: species of Cincturorhynchus with a prostate stylet type II that is a doublewalled, ca. $49 \mu \mathrm{m}$ long, curved tube with a ca. $40 \mu \mathrm{m}$ broad proximal base carrying one spine of ca. $41 \mu \mathrm{m}$ long. Prostate stylet type III with a semicircular to horseshoe-shaped proximal base carrying one group of short (ca. $16 \mu \mathrm{m}$ ) and one group of long (ca. $34 \mu \mathrm{m}$ ) spines.

\section{Discussion}

The new species can easily be placed within the taxon Cincturorhynchus Evdonin, 1970, as it shows all the diagnostic characters of this taxon: paired seminal vesicles, a small prostate vesicle type II connected to a prostate stylet type II, a prostate stylet type III consisting of a horseshoe-shaped base carrying large teeth, a prostate vesicle type III associated with a prostate stylet type III and a terminal female bursa.

Apart from C. monaculeus, two other species of this taxon are known: C. karlingi Schockaert, 1982 from the African east coast (see Schockaert, 1982) and Cincturorhynchus ruber Evdonin, 1970 from the Possjet Bay (Japanese Sea, Russia; see Evdonin, 1970, 1977). The three species can easily be distinguished based on differences in the construction of the prostate stylets. In C. ruber, the prostate stylet type II is a simple, double-walled tube. In the two other species, the base of this tube is enlarged and carries a number of spines, one in C. monaculeus, four to seven in $C$. karlingi. The single spine present on the prostate stylet type II of $C$. monaculeus is also much larger than each of the spines in $C$. karlingi. The prostate stylet type III in all three species consists of a horseshoe-shaped base carrying a number of spines. Differences between the species can be found in the number and form of the spines. Judging from the drawings and the description of C. ruber by Evdonin (1970), it carries a limited number of relatively small spines. In $C$. karlingi and $C$. monaculeus, the spines are more numerous and larger. In $C$. monaculeus they are longer and more slender than in $C$. karlingi. In $C$. karlingi they are more triangular in shape, having the form of broad blades.
Duplexostylus winsori n. gen., n. sp. (Figs 8c-e, 10C)

Distribution: Hinchinbrook Channel (Townsville area, Queensland), sand from a tidal flat, 20 Nov. 1988 and in Oct. 1991 (type locality).

Material examined: drawings of live animals by Dr Dittmann; three whole mounts, one of them designated holotype (UH no. 333), the other two paratypes (UH nos 334-335); one sagittally sectioned animal.

Etymology: the genus name refers to the fact that the species has a copulatory organ resembling a duplex-type (terminology of Karling, 1956), combined with a stylet; the species epithet is in honour of Mr Leigh Winsor (Townsville, Australia).

\section{Description}

The animals are $0.6-0.8 \mathrm{~mm}$ long, colourless and without eyes. The epidermis is syncytial, ca. $5 \mu \mathrm{m}$ high with cilia $3 \mu \mathrm{m}$ long. The basal membrane is ca. $1 / 4$ of the epithelium height thick. The presence of rhabdites could not be determined with certainty. Caudal glands are well developed.

The proboscis is about $20 \%$ of the body length long. The proboscis sheath is lined with a nucleated epithelium and is surrounded by an inner circular and an outer longitudinal muscle layer. There are no nuclei at the junction of sheath and cone epithelia. The organisation of the retractor system could not be determined. There are six bundles of fixators.

The pharynx is in the first body half and inclined slightly forwards. The distal part of the prepharyngeal cavity is lined with a pseudociliation, the remaining part by a membranous epithelium. It is surrounded by an inner circular and an outer longitudinal muscle layer. The circular layer is lacking in the proximal $1 / 3$ of the cavity. The epithelium of the pharyngeal lumen lacks nuclei. Three types of pharyngeal glands enter the distal part of the pharyngeal lumen, two eosinophilic ones with a basophilic one in between. The proximal pharynx opening is surrounded by four hard teeth.

The gonads are unpaired. The small testis lies just behind the pharynx at the right hand side of the body. The ovary lies caudally from the gonopore. It is ovoid and slightly curved, with the oocytes arranged in a row. The vitellarium extends dorsally at 
the right hand side of the body. The gonopore is at $80 \%$ and can be closed by a strong sphincter (Fig. 8e: gp). The common genital atrium (Fig. 8e: ga) is lined with a high, nucleated epithelium and surrounded by longitudinal muscles.

The sperm-conducting system consists of a single seminal vesicle (Fig. 8e: vs), a prostate ves- icle type IV (Fig. 8e: pv4) and a prostate stylet type III (Figs 8e: st3, 8c, 10c). The seminal vesicle is lined with a membranous epithelium and surrounded by a circular muscle layer. It narrows somewhat towards the prostate vesicle and enters it proximally (conjuncta-type copulatory organ). Within the prostate vesicle it is no longer visible,

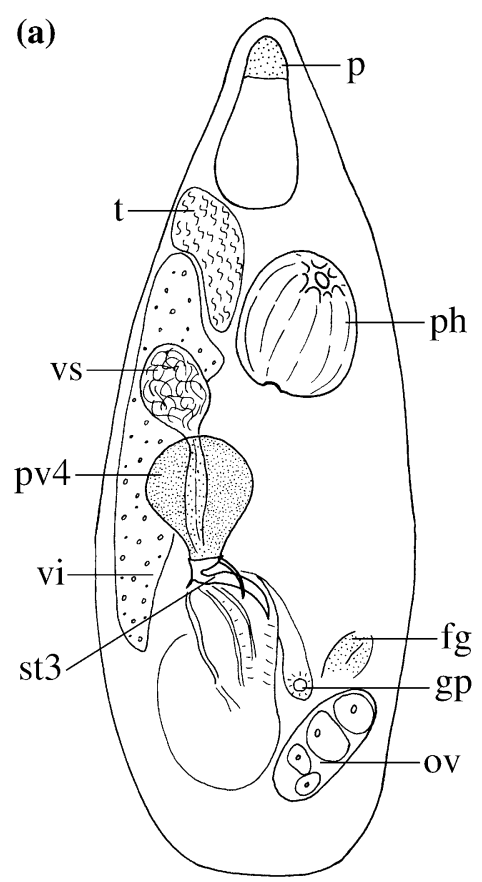

(b)

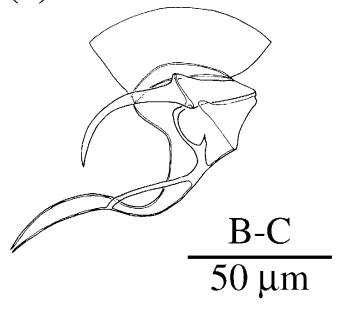

(d)

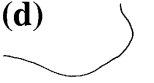

$b \subset$

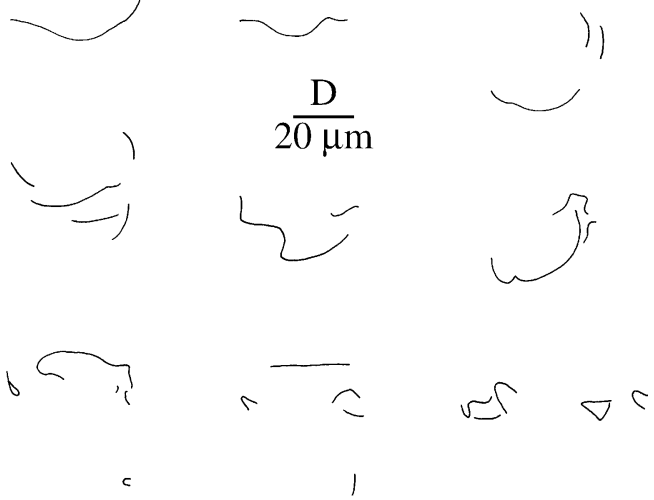

(c)

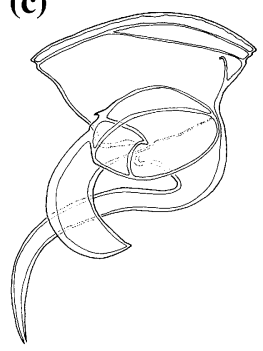

(e)

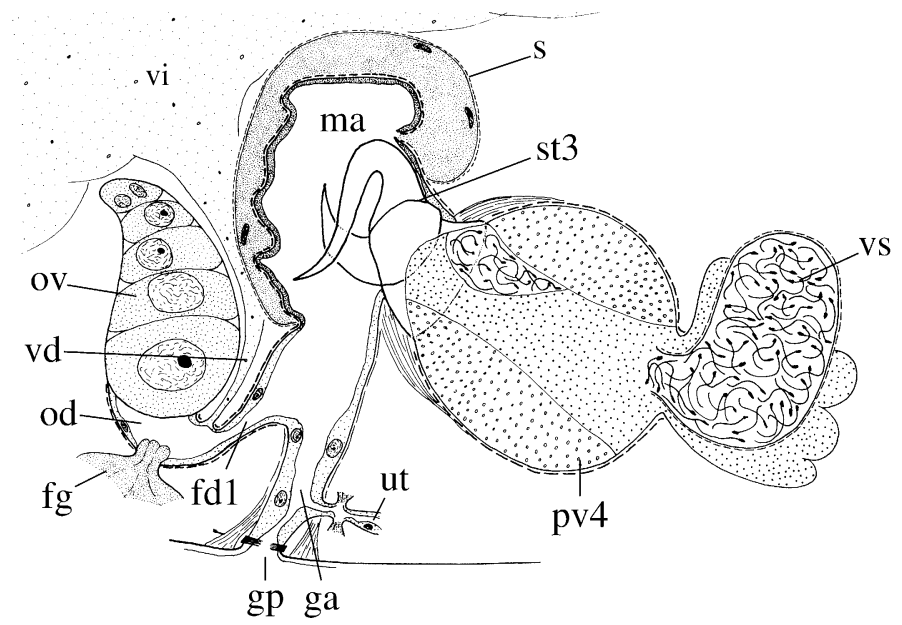

Figure 8. Duplexostylus rowei n. gen., n. sp. (a) General organisation (from a live specimen). (b) Prostate stylet type III (from the holotype). Duplexostylus winsori n. sp. (c) Prostate stylet type III (from the holotype). (d) Consecutive sections through the prostate stylet type III (top left: proximal part of the stylet; bottom right: distal part of the stylet). (e) Reconstruction of the atrial organs from the right side. 
except for a small part in the distal end of the vesicle. The prostate vesicle is very large and globular. It is surrounded by a circular muscle layer, distally supplemented with thicker longitudinal muscles, which connect the vesicle with the proximal part of the male atrium (protractors of the vesicle). It contains a coarse-grained and a finegrained basophilic secretion. The nucleated parts of the interposed prostate glands are outside the vesicle. The prostate vesicle is connected to the complex prostate stylet type III (Figs 8e: st3, 8c, 10c). This stylet consists of a plate, which is proximally folded in the shape of a funnel and continues distally as a gutter-like to tubular spine, as is shown by consecutive sections through the stylet (see Fig. 8d). The transition from funnel to spine is rather abrupt, and the proximal part of the curved spine runs perpendicularly to the funnel. At this transition, a complex fold of the funnel forms a second very broad spine, which curves in the opposite direction to the first spine. The stylet (funnel + first spine) is $146-183 \mu \mathrm{m}$ long $(m=162 \mu \mathrm{m} ; n=3)$ and $71-86 \mu \mathrm{m}$ broad proximally $(m=77 \mu \mathrm{m} ; n=3)$. The second spine is $46-$ $76 \mu \mathrm{m}$ long $(m=57 \mu \mathrm{m} ; n=3)$. The male atrium leaves the common atrium dorsally. It is lined with a pseudocuticula and surrounded by circular muscles. A large muscular septum (Fig. 8e: s) encloses the larger part of the male atrium asymmetrically, only dorsally (copulatory organ of the duplex-type; terminology of Karling, 1956). It does not enclose the prostate vesicle.

The female system is very simple. The female duct type I (Fig. 8e: fd1) leaves the common genital atrium caudally. It is lined with a high epithelium and surrounded by circular muscles. It broadens towards the ovary (Fig. 8e: ov). A large bundle of eosinophilic glands (Fig. 8e: fg) enters through the ventral wall of this broader space, while the vitelloduct (Fig. 8e: vd) enters through its dorsal wall.

The uterus (Fig. 8e: ut) is of the normal polycystidid construction. It leaves the common genital atrium out of its frontal wall.

\section{Diagnosis}

Duplexostylus n. gen.: Polycystididae without eyes. Unpaired gonads and a single vitellarium. With only one seminal vesicle. Male atrial system of the duplex type, with a prostate vesicle type IV. Septum only enclosing the male atrium, and only dorsally. Prostate vesicle connected to a prostate stylet type III, which consists of a plate folded into the shape of a broad funnel that distally continues as a spine. At the transition from funnel to spine the stylet carries a second spine. Female system with a female duct type I that connects the ovary with the common genital atrium. Female glands present. Type species: $D$. winsori $\mathrm{n}$. sp.

Duplexostylus winsori $\mathrm{n}$. $\mathrm{sp} .:$ species of Duplexostylus with prostate stylet type III ca. $162 \mu \mathrm{m}$ long (funnel + first spine) and ca. $77 \mu \mathrm{m}$ broad. Second spine very broad, ca. $57 \mu \mathrm{m}$ long.

\section{Discussion}

See the discussion on Duplexostylus rowei n. gen., n.sp.

Duplexostylus rowei n. gen., n. sp. (Figs $8 \mathrm{a}-\mathrm{b}$, 10d)

Distribution: Townsville (Queensland), muddy sand with much detritus from a seagrass field along 'The Strand' opposite Oxley Street, 25 Aug. 1996 (type locality).

Material examined: one animal studied alive and mounted (holotype: UH no. 336).

Etymology: dedicated to Prof. Dr Richard Rowe (Townsville, Australia).

\section{Description}

This species is almost identical to D. winsori. As far as could be seen on the live specimen (Fig. 8a), the only difference with that species is the form of the second spine of the prostate stylet type III (Figs 8b, 10d). This spine is much narrower and more elegant compared to that of the former species. The stylet is a bit smaller: $126 \mu \mathrm{m}$ long and $52 \mu \mathrm{m}$ broad proximally. The second spine is $47 \mu \mathrm{m}$ long.

\section{Diagnosis}

Duplexostylus rowei $\mathrm{n}$. sp.: species of Duplexostylus with prostate stylet type III ca. $126 \mu \mathrm{m}$ long (funnel + first spine) and ca. $52 \mu \mathrm{m}$ broad. Second spine very narrow, ca. $47 \mu \mathrm{m}$ long. 


\section{Discussion}

Unpaired gonads are only found in a restricted number of taxa within the Polycystididae and only a few of them have a prostate vesicle type IV: Annulorhynchus adriaticus Karling, 1956, the species of Danorhynchus Karling, 1955 (only ovary unpaired), the species of Gallorhynchus Schockaert, 1971, Koinocystella inermis Karling, 1952, Neopolycystis tridentata Karling, 1955 (only ovary unpaired), the species of Psammopolycystis Meixner, 1938, the species of Scanorhynchus Karling, 1955, the species of Stradorhynchus nov. gen (this contribution) and Syltorhynchus schockaerti Noldt, 1989 (only ovary unpaired). Most of these also have a prostate stylet type III, and only in K. inermis Karling, 1952, Gallorhynchus simplex Schockaert \& Brunet, 1971 and species of Stradorhynchus is it lacking. In none of these species, however, is the prostate stylet type III directly connected to the prostate vesicle type IV (see Artois \& Schockaert, 2003), as is the case in both species of Duplexostylus.

Another typical feature of Duplexostylus is the asymmetrical septum that surrounds the dorsal side of the male atrium, which indicates that the male system is of the conjuncta-duplex type. The presence of such a septum is rare in polycystidids, and only occurs in the four species of Duplacrorhynchus Schockaert \& Karling, 1970 and in Yaquinaia microrhynchus Schockaert \& Karling, 1970 (see Artois \& Schockaert, 2003). In these taxa, the septum is placed symmetrically around the male atrium and also encloses at least a part of the prostate vesicle (exc. in Duplacrorhynchus heyleni Artois \& Schockaert, 1999).

The combination of unpaired gonads, the presence of a prostate vesicle type IV directly connected to a prostate stylet type III, and the presence of an asymmetrical septum are unique within the Polycystididae, and clearly warrant the erection of a new genus. The relationships with the other taxa of Polycystididae are unclear.

Paraustrorhynchus caligatus n. sp. (Figs 9, 10e-f) Distribution: North Stradbroke Island (Queensland), in a sea grass field in the tidal zone, 13 Aug. 1996 (type locality); same locality, Adams Beach, in sea grasses (Zostera) from a tidal pool, 16 Sept. 1996.
Material examined: two specimens studied alive and mounted (one from each locality), one of them designated holotype (UH no. 337).

Etymology: the prostate stylet type II is bootshaped. Caliga (Lat.): boot.

\section{Description}

Animals about $1 \mathrm{~mm}$ long, yellowish to dark green pigmented. They have two eyes. The internal organisation corresponds to that of Paraustrorhynchus pacificus Karling \& Schockaert, 1977, as far as it could be seen in the live specimens (Fig. 9a).

The male atrium (Fig. 9a: ma) is proximally very broad, and contains the prostate stylet type II (Figs 9a: st2, 9b, 10e) and a plate-like prostate stylet type III (Figs 9a: st3, 9c, 10f). The prostate stylet type II is a double-walled tube, $40-58 \mu \mathrm{m}$ long $(n=2)$. Its distal end makes a $45^{\circ}$-turn, giving the stylet the overall appearance of a boot. It is connected to a prostate vesicle type II (Fig. 9a: pv2). The internal stylet can be followed almost throughout the whole length of the external one.

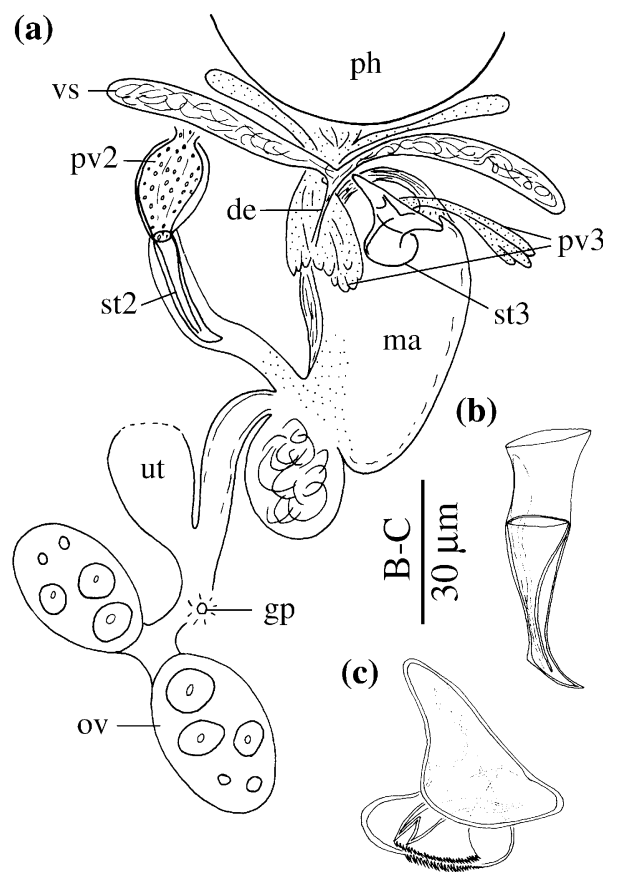

Figure 9. Paraustrorhynchus caligatus n. sp. (a) Atrial organs (from a live specimen). (b) Prostate stylet type II (from the holotype). (c) Prostate stylet type III (from the holotype). 

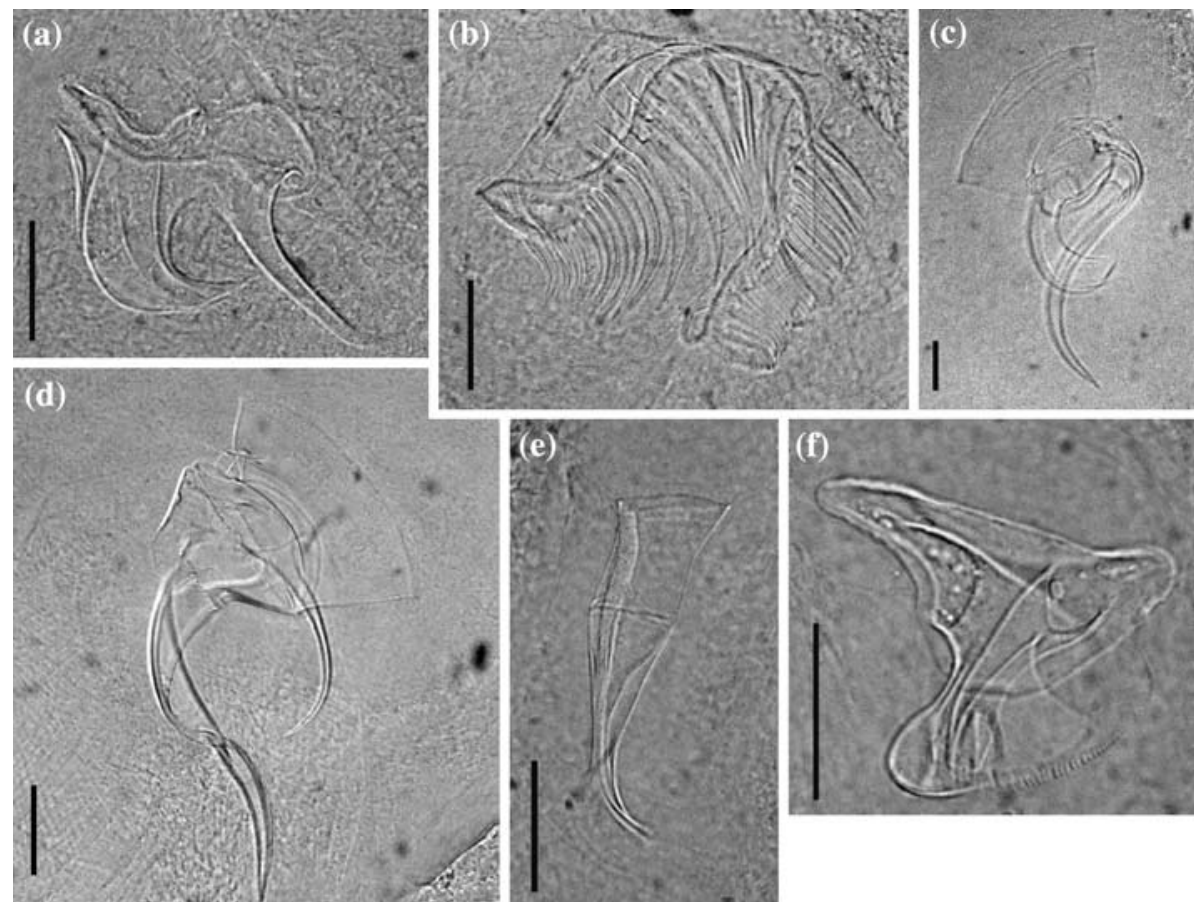

Figure 10. Cincturorhynchus monaculeus n. sp. (a) Prostate stylet type II (from the holotype). (b) Prostate stylet type III (from the holotype). Duplexostylus winsori n. gen., n. sp. (c) Prostate stylet type III (from the holotype). Duplexostylus rowei n. gen., n. sp. (d) Prostate stylet type III (from the holotype). Paraustrorhynchus caligatus n. sp. (e) Prostate stylet type II (from the holotype). (f) Prostate stylet type III (from the holotype). Scale bars: $20 \mu \mathrm{m}$.

The complex prostate stylet type III consists of a proximal plate, which serves as a base from which two arms depart. These arms protrude distally and both broaden towards their distal end. This prostate stylet could only be measured on one specimen. One of the arms is $23 \mu \mathrm{m}$ long and $19 \mu \mathrm{m}$ broad at its distal rim, which is completely serrated. At the base of this arm there is a triangularshaped fold. The other arm is $37 \mu \mathrm{m}$ long and $33 \mu \mathrm{m}$ broad at its distal end. The distal end of this plate is only partly serrate. The distal ends of both arms are at the same level. The prostate stylet type III is associated with a prostate vesicle type III (Fig. 9a: pv3). The ejaculatory duct (Fig. 9a: de) enters the male atrium close to this organ. More distally the male atrium is filled with many sperm.

\section{Diagnosis}

Paraustrorhynchus caligatus n. sp.: species of Paraustrorhynchus with a ca. $49 \mu \mathrm{m}$ long, bootshaped prostate stylet type II. Prostate stylet type III consisting of a proximal plate, carrying two arms, both of which broaden towards their distal end. One arm is ca. $23 \mu \mathrm{m}$ long with a completely serrated, ca. $19 \mu \mathrm{m}$ broad distal rim; the other one is ca. $37 \mu \mathrm{m}$ long and has a partially serrated, ca. $33 \mu \mathrm{m}$ broad distal rim.

\section{Discussion}

The taxon Paraustrorhynchus Karling \& Schockaert, 1977 is characterised by a unique combination of features (see Karling \& Schockaert, 1977): paired gonads, a large male atrium without a real male bursa, with a prostate vesicle type II connected to a prostate stylet type II, with a complex prostate stylet type III associated with a prostate vesicle type III, the ejaculatory duct ending in the male atrium very near to the prostate stylet type III, with an accessory glandular vesicle of type I, proximal part of male atrium with a large muscle bulb, with a female duct type I with terminal female glands but without female bursa (exc. P. elixus (Marcus, 1954) Karling \& Schockaert, 1977 which has a female bursa) and with- 
out insemination ducts. All these characters are present in $P$. caligatus. Only the absence of the insemination ducts should be checked on sectioned material.

The hard parts of the male system of $P$. caligatus are very much like those of $P$. pacificus, but some clear and consistent differences can be found between the two species. The prostate stylet type II of both species is a rather simple tube, evenly curved in $P$. pacificus, with the typical boot-like shape in $P$. caligatus. Moreover, this stylet is much longer in $P$. pacificus (ca. $125 \mu \mathrm{m}$ ) than in $P$. caligatus (ca. $49 \mu \mathrm{m}$ ). The two arms of the prostate stylet type III of $P$. caligatus broaden evenly towards their distal end, giving them the shape of broad plates. One arm has a completely serrated distal rim, the other one has only the middle part of the distal rim serrated. In P. pacificus, both arms are much narrower proximally, abruptly widening at their distal end. One of the arms has a completely serrated distal rim, while the other one is somewhat bifid distally, with a (very small) part serrated, and the other part not serrated. Moreover, the prostate stylet type III of $P$. pacificus is much larger (ca. $140 \mu \mathrm{m}$ ) than that of $P$. caligatus (ca. $37 \mu \mathrm{m})$.
Apart from those two species, a third species of Paraustrorhynchus has been described from Brazil: $P$. elixus. This species is, however, very different from the other two. Its hard parts have a totally different shape (prostate stylet type II a very simple small hook, prostate stylet type III with two articulating parts) and it has a female bursa. For a thorough discussion of this species and a comparison with $P$. pacificus we refer to Karling \& Schockaert (1977).

Polycystis australis n. sp. (Figs 11, 14a)

Distribution: Arrawarra (New South Wales), brown algae from a tidal pool in the mid-eulittoral, 28 Aug. 1996 (type locality). Coffs Harbour (New South Wales), Mullaway headland, brown and red algae from rock pools, 24 Jul. 2003.

Material examined: several animals studied alive; four whole mounts, one of which is designated holotype (UH no. 338), another one paratype (UH no. 339); one serially sectioned specimen (horizontally sectioned; designated paratype: UH no. 340).

Etymology: the species name refers to its distribution in the southern hemisphere. Australis (Lat.): southern.

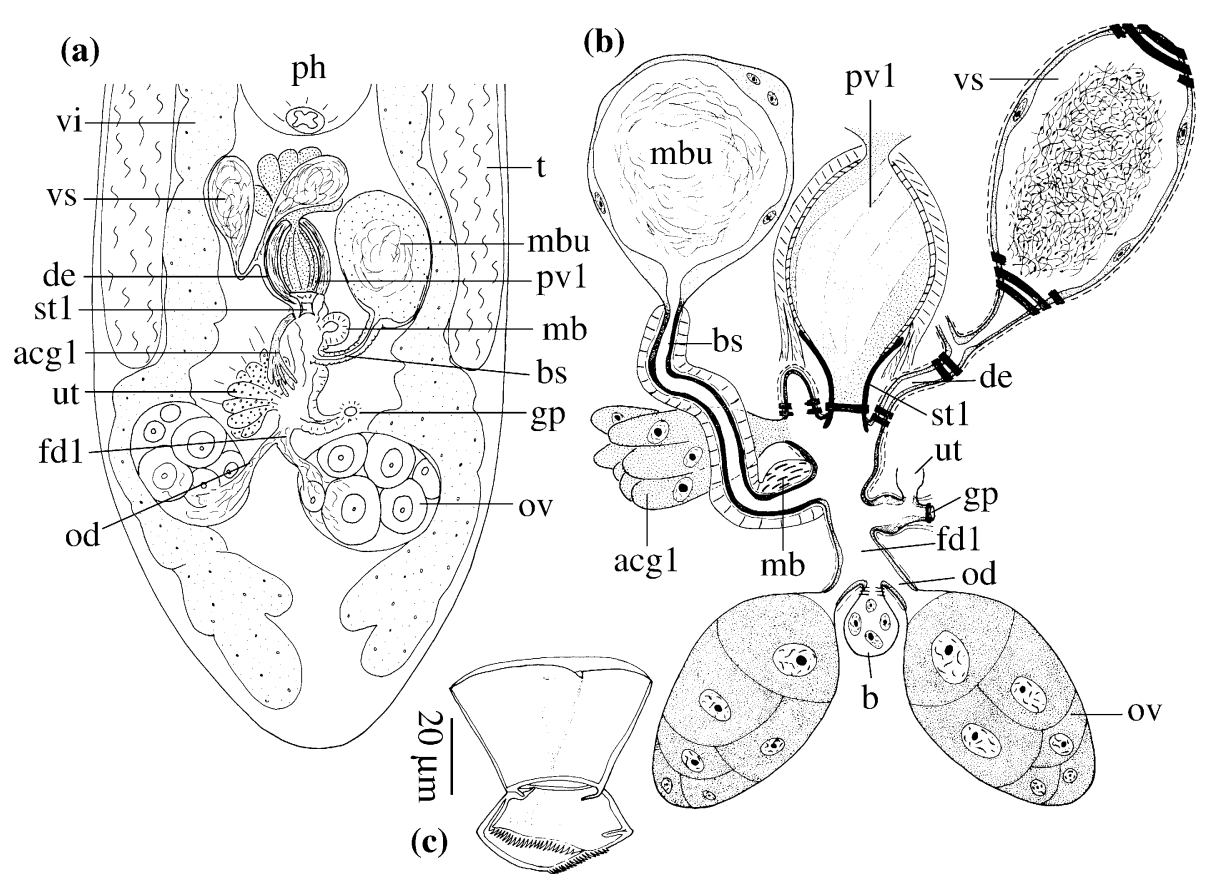

Figure 11. Polycystis australis n. sp. (a) Caudal body end with the atrial organs (from a live specimen). (b) Horizontal reconstruction of the atrial organs from above. (c) Prostate stylet type I (from the holotype). 


\section{Description}

The animals are colourless, $1.5-2.2 \mathrm{~mm}$ long and have two eyes. Construction of epidermis, proboscis, pharynx and genital system as in Polycystis naegelii Kölliker, 1845.

The prostate stylet type I (Fig. 11a, b: st1, 11c, 14a) is a double-walled funnel, showing a constriction in about its middle and broadening again distally. It is $48-58 \mu \mathrm{m}$ long $(m=52 \mu \mathrm{m} ; n=3)$ and $30-53 \mu \mathrm{m}$ broad proximally $(m=45 \mu \mathrm{m} ; n=3), 23-$ $38 \mu \mathrm{m}$ distally $(m=32 \mu \mathrm{m} ; n=3)$. At the constriction it is $15-25 \mu \mathrm{m}$ broad ( $m=19 \mu \mathrm{m} ; n=3)$. The distal rim of the outer stylet is partly toothed. The internal stylet is only visible in the proximal half of the outer one. The stylet is connected to a prostate vesicle type I (Fig. 11a, b: pv1), which contains two types of secretion and is surrounded by two spirally running muscle layers. The inner muscle layer attaches to the inner side of the outer stylet, the outer layer is continuous with the muscles of the male atrium. The bursal stalk (Fig. 11a, b: bs) leaves the male atrium just before this itself enters the common genital atrium. It is surrounded by a thick circular muscle layer and lined with a pseudocuticula. At the opening of the bursal stalk into the male atrium, the circular muscle layer is asymmetrically thickened. A real asymmetrical muscle bulb, as is found on the bursal stalk in P. naegelii and Polycystis ali Schockaert, 1982 is, however, lacking.

At the bifurcation of the two oviducts, a very small muscular female bursa (Fig. 11b: b) is present. It contains many sperm and nuclei.

\section{Diagnosis}

Polycystis australis n. sp.: unpigmented species of Polycystis. Stalk of male bursa with a distal, asymmetrical sphincter, but without asymmetrical muscle bulb. Stylet broad and short, with a symmetrical distal part without a slit and with the distal rim only partly serrated. Distal rim not folded back. Stylet without a spur or hook. Stylet ca. $52 \mu \mathrm{m}$ long; ca. $45 \mu \mathrm{m}$ broad proximally; ca. $32 \mu \mathrm{m}$ broad distally and ca. $19 \mu \mathrm{m}$ broad in about its middle

\section{Discussion}

This species undoubtedly belongs to the taxon Polycystis Kölliker, 1845 as diagnosed by Artois \&
Schockaert (1998). At the moment five species are recognised. For one of these species, $P$. ali, Karling (1986) described three different forma's: 'Somali', 'California', and 'Galapagos'.

The species of Polycystis all have a large male bursa, ending in the distal part of the male atrium. In most species, the bursal stalk is distally provided with a very asymmetrical muscle bulb (see Artois \& Schockaert, 1998). Only in Polycystis gabriellae (Marcus, 1948) Karling, 1952 and $P$. australis is this muscle bulb replaced by an asymmetrical sphincter. The bursal stalk of both species is also much longer and very muscular.

The prostate stylets of all species of Polycystis are rather short and broad, except for the stylet of $P$. gabriellae, which is somewhat longer and has a rather long distal tube. The stylet of $P$. australis is similar to that of $P$. ali, especially that of $P$. ali forma 'California. Typical of these two taxa is the fact that the stylet is symmetrical, lacking the distal asymmetrical outgrowth of Polycystis orientalis Evdonin, 1968. It also lacks the distal hook typical of Polycystis hamata Karling, 1986 and lacks a spur as in $P$. naegelii. The stylets of $P$. ali forma 'Somali' and $P$. ali forma 'Galapagos' are more similar to that of $P$. australis and $P$. ali forma 'California', but differ in that the distal end is circular and broad, with the edges folded back, so that they form a sort of gutter that surrounds the stylet. The stylet of $P$. australis differs from that of $P$. ali forma 'California' in two important ways. It lacks the distal split that is very prominent in P. ali forma 'California', and the distal rim of the stylet is not serrated over the whole of its length, whereas in $P$. ali forma 'California' it is completely serrated with large, sturdy teeth.

Another typical feature of $P$. australis is the lack of any pigmentation. Within Polycystis, only $P$. hamata and some specimens of $P$. ali forma 'California' lack pigmentation. In the latter forma unpigmented and weakly pigmented specimens are known (see Karling, 1986).

Stradorhynchus caecus n. gen., n. sp. (Figs 12ac, $14 \mathrm{c}$ )

Distribution: North Stradbroke Island (Queensland): Myora, on a beach behind mangroves, near to a creek, 14 Aug. 1996 (type locality); same locality, Dunwich, in a sea grass-bed in the eulittoral, 21 Sept. 1996. Coffs Harbour (New 
South Wales), Coffs creek, about $150 \mathrm{~m}$ west of the bridge, north bank, dark silty sand and among oysters, 23 Jul. 2003.

Material examined: four specimens studied alive; three mounted (one of which designated holotype: UH no. 341) and one sagittally sectioned animal.

Etymology: the genus name refers to Stradbroke Island, whereas the species epithet refers to the absence of eyes. Caecus (Lat.): blind.

\section{Description}

The animals are colourless, $0.5 \mathrm{~mm}$ long and have no eyes. The epidermis is syncytial, $4 \mu \mathrm{m}$ high, with cilia $2 \mu \mathrm{m}$ long. The basal membrane is ca. $1 \mu \mathrm{m}$ thick. The rhabdites, which are lacking around the proboscis pore, are less than half the epithelium height long. Caudal glands are well developed.

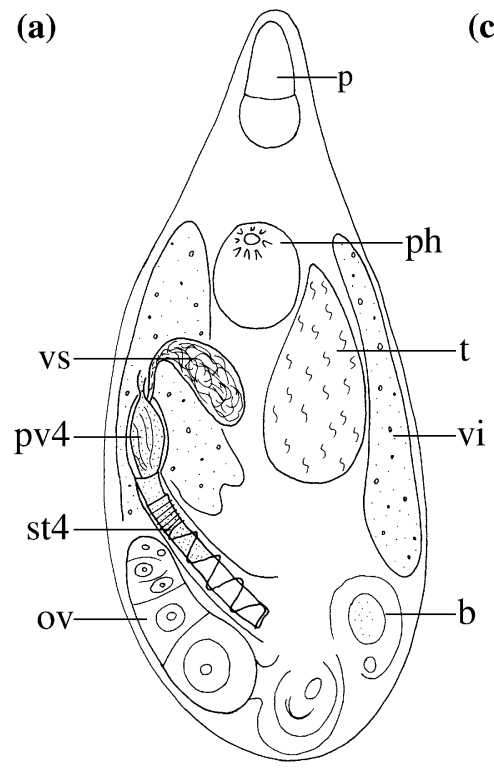

(c)

(b)

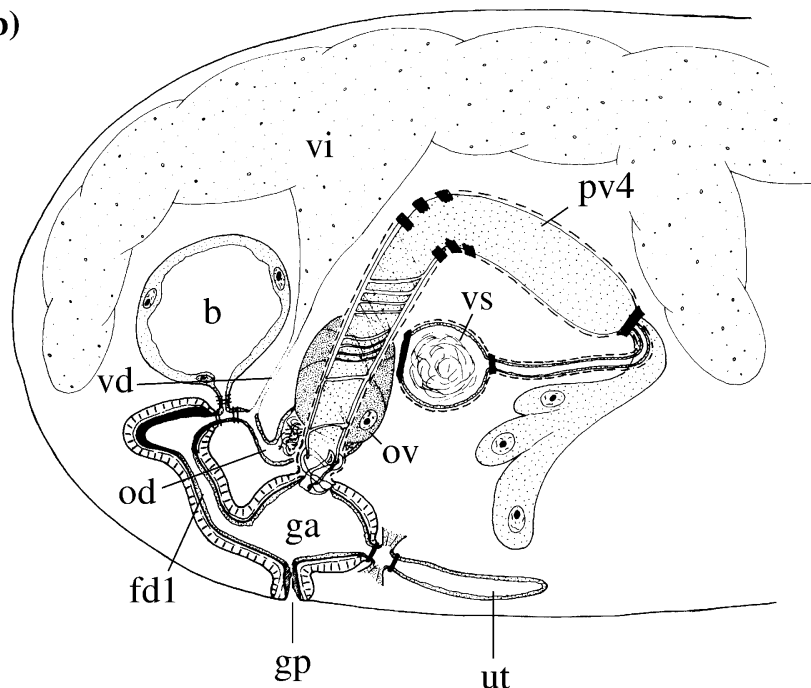

(d)

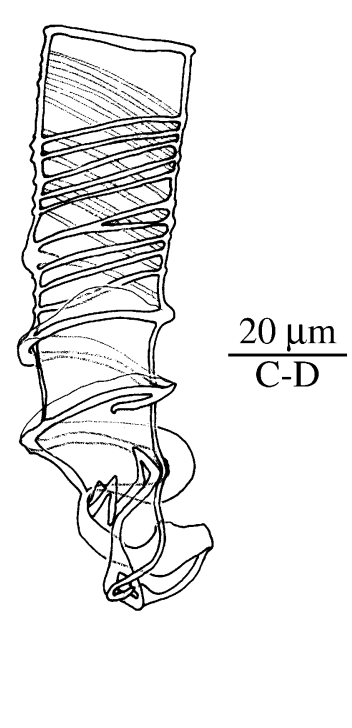

(d)

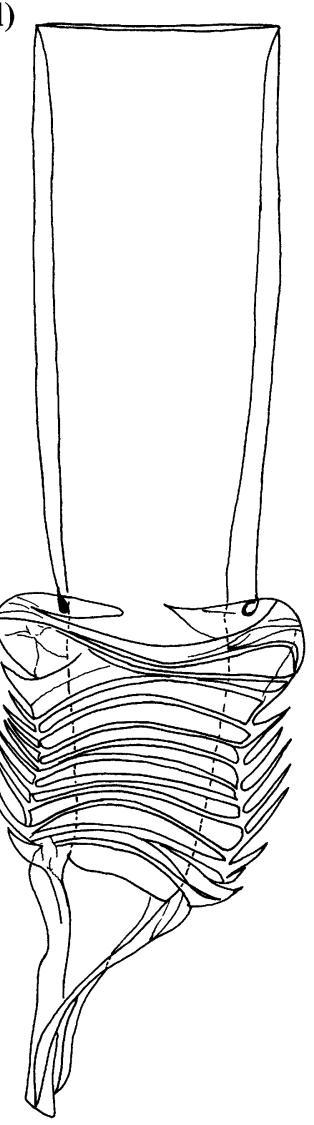

Figure 12. Stradorhynchus caecus n. gen., n. sp. (a) General organisation (from a live specimen). (b) Reconstruction of the atrial organs from the right side. (c) Single-walled prostate stylet type (from the holotype). Stradorhynchus terminalis n. gen., n. sp. (d) Single-walled prostate stylet type (from the holotype). 
The proboscis (Fig. 12a: p) is about $20 \%$ of the body length long. In the living animals a small apex was observed. The proboscis sheath is surrounded by internal circular and external longitudinal muscles, and is lined with an anucleated epithelium. The circular muscles are absent around the distal third of the cavity. There are no nuclei at the junction between sheath and cone epithelia. There are two pairs of integument retractors, one dorsal and one ventral pair. The exact number of proboscis retractors could not be determined with certainty, but there are probably three pairs of them. There are six bundles of fixators. A large glandular complex is situated near the brain, with the gland necks extending beside the proboscis bulb.

The pharynx (Fig. 12a: ph) is situated in the anterior body half and inclined slightly forwards. It is approximately $15 \%$ of the body length in diameter. Four teeth are present around the proximal pharyngeal opening. The prepharyngeal cavity is lined with a membranous, anucleated epithelium. About in the middle of the cavity, the epithelium forms a ring of pseudociliation. The cavity is surrounded by an internal circular and an external longitudinal muscle layer. The circular layer is absent around the most proximal third of the cavity. The pharyngeal lumen is lined with a low, anucleated epithelium. There are three types of pharyngeal glands, one basophilic and two eosinophilic.

The gonads are unpaired. The testis (Fig. 12a: t) is very long and lies at the right hand-side of the pharynx, from where it stretches out backwards. The ovoid ovary (Fig. 12a-b: ov) lies at the caudal body end. The vitellaria (Fig. 12a-b: vi) are paired and caudally connected to each other by means of a narrow 'bridge' from which the single vitelloduct departs. The common genital pore (Fig. 12b: gp) lies at $80 \%$ of the body length and can be closed by a strong sphincter. The common atrium (Fig. 12b: ga) is lined with a low anucleated epithelium and surrounded by internal longitudinal and external circular muscles.

The male genital atrium leaves the common genital atrium dorsally. It is surrounded by a circular muscle layer, but is not lined with a visible epithelium. The prostate stylet type IV (Figs 12ab: st $4,12 \mathrm{c}, 14 \mathrm{c}$ ) fills the male atrium completely. It is $101-109 \mu \mathrm{m}$ long $(n=2)$ and $26 \mu \mathrm{m}$ wide proximally $(n=2), 15-21 \mu \mathrm{m}$ distally $(n=2)$. It is ornamented with spirally running ridges over the whole of its length. The distal tip of the stylet is very complex, showing several ridges and two flaplike projections. The stylet is connected to a long and pyriform prostate vesicle type IV (Fig. 12a-b: pv4), which contains only one type of eosinophilic secretion. The prostate secretion continues very far into the stylet, almost to the distal tip of the stylet, which itself protrudes into the common genital atrium. The prostate vesicle is surrounded by circular muscles, which are continuous with the circular muscles surrounding the male atrium. The ejaculatory duct is surrounded by circular muscles and lined with a low, anucleated epithelium, as is the unpaired seminal vesicle. Distally, it enters the prostate vesicle through a muscular pore.

The female duct type I (Fig. 12b: fd1) is lined with a low anucleated epithelium and surrounded by a thick external circular muscle layer and an internal longitudinal layer. It leaves the common genital atrium caudally. Proximally it widens to form an ovoid space that is lined with a very thick pseudocuticula. The narrow proximal part of the female duct leaves out of the frontal wall of this space. It is surrounded by a weak circular muscle layer and is connected to a large female bursa (Fig. 12a-b: b) through a short, weakly muscular bursal stalk. More proximal from this bursal stalk, the female duct is bent ventrally and receives the oviduct (Fig. 12b: od). This oviduct is surrounded by weak circular muscles and lined with a low anucleated epithelium. Its most proximal part is widened and contains sperm.

The uterus (Fig. 12b: ut) opens through the frontal wall of the common genital atrium and is of the normal polycystidid construction.

\section{Diagnosis}

Stradorhynchus n. gen.: Polycystididae with two pairs of integument retractors and (probably) three pairs of proboscis retractors. Gonads and vitellarium unpaired. Seminal vesicle unpaired. Male atrial system with a prostate vesicle type IV, connected to a prostate stylet type IV. Female system with a female duct type I, proximally forming a wide space lined with pseudocuticula. Female bursa present, connected to part of the female duct proximal from the widening. Oviduct departs from this proximal part of the female duct. 
Oviduct widens to sperm-filled space near the ovary. Type species: $S$. caecus n. sp.

Stradorhynchus caecus n. sp.: species of Stradorhynchus without eyes. Stylet ca. $105 \mu \mathrm{m}$ long with spirally running ridges over its full length. Stylet with a complex distal tip.

\section{Discussion}

See the discussion on Stradorhynchus terminalis n. sp.

Stradorhynchus terminalis n. gen., n.sp. (Figs 12d, 14d)

Synonymy: 'Stradorhynchus terminalis' in Willems et al. (2006)

Distribution: Coffs Harbour (New South Wales), Coffs creek, south bank, about $75 \mathrm{~m}$ west from the bridge, fine-grained sand and algae in a channel, 23 Jul. 2003 (type locality); same locality, about $100 \mathrm{~m}$ west from the bridge amongst mangroves on the north shore of the creek; sandy to silty sediment, 15 Jul. 2003. Coffs Harbour, Campbell beach, medium coarse sand from the mid-eulittoral to the north of a projection of the beach, 17 Jul. 2003.

Material examined: several specimens studied alive; three whole mounts, one of them designated holotype (UH no. 342), three serially sectioned specimens.

Etymology: the species name refers to the fact that the spirally running ridges are restricted to the distal tip of the stylet.

\section{Description}

Habitus and internal organisation is identical to that of $S$. caecus (see Fig. 12a-b), except for the fact that $S$. terminalis has eyes and a somewhat reddish colouration owing to parenchymal pigment. The only difference with $S$. caecus is the shape and size of the prostate stylet type IV (Figs 12d, 14d), which could be measured in the holotype only because of the poor quality of the other whole mounts. The stylet is $185 \mu \mathrm{m}$ long and $40 \mu \mathrm{m}$ wide proximally, $11 \mu \mathrm{m}$ distally. It is ornamented with many spirally running ridges, which are restricted to the distal third of the stylet, giving the stylet the resemblance of a 'stripped-off sock'. The stylet tapers towards its complex distal tip.

\section{Diagnosis}

S. terminalis n. sp.: species of Stradorhynchus with eyes. Stylet ca. $185 \mu \mathrm{m}$ long. Spirally running ridges restricted to the distal half of the stylet.

\section{Discussion}

The presence of only one testis and one ovary in combination with a prostate vesicle type IV connected to a prostate stylet type IV is unique within the Polycystididae. The most similar situation is found in $K$. inermis, which has unpaired gonads and a prostate vesicle type IV. Moreover, both species of Stradorhynchus and K. inermis have a proximal widening of the oviduct, which functions as a seminal receptacle. The two taxa, however, clearly differ in two respects: the species of Stradorhynchus have a terminal female bursa and have a prostate stylet type IV. Both are lacking in $K$. inermis, which has an unarmed cirrus.

Another similarity between $K$. inermis and the species of Stradorhynchus is the fact that the proboscis retractor system consists of three pairs of proboscis retractors and two pairs of integument retractors, whereas in most Polycystididae there are four pairs of proboscis retractors and one pair of (ventral) integument retractors (see Artois \& Schockaert, 1999). This ' $3+2$ ' situation is also found in some other species that have a prostate vesicle type IV connected to a prostate stylet type IV: species of Djeziraia Schockaert, 1971, Phonorhynchoides Beklemishev, 1927, Yaquinaia Schockaert \& Karling, 1970 and Annalisella Karling, 1978. All these species, however, have paired gonads.

The prostate stylet type IV of Annalisella bermudensis Karling, 1978 is remarkably similar to that of the species of Stradorhynchus, especially to that of $S$. caecus. In both species the stylet has spirally running ridges, 4-5 in A. bermudensis, ca.10 in $S$. caecus. The distal tip of the stylet is hook-shaped in both species, but it is much more complex in $S$. caecus. In S. terminalis, the ridges are many and 'packed together' at the distal tip of the stylet. A. bermudensis clearly differs from the species of Stradorhynchus as it has paired gonads, an accessory glandular vesicle type IV connected to an accessory stylet type IV, and a separate male and female gonopore. Whether the similarities in 
shape of the stylet between $A$. bermudensis and both species of Stradorhynchus reflect a common origin is therefore doubtful. A very similar stylet is also found in Astrotorhynchus bifidus (McIntosh, 1874) Graff, 1905 (Trigonostomidae), a taxon that is clearly not related.

Triaustrorhynchus armatus n. gen., n. sp. (Figs 13, 14b)

Distribution: Lady Bay (Sydney, New South Wales), north side of the beach, coarse shell gravel from between rocks, 6 Oct. 1996 (type locality).

Material examined: observations on one live animal, which was subsequently mounted (holotype: UH no. 343).

Etymology: the genus name reflects the similarity to Austrorhynchus, but indicates that the new taxon has three stylets; the epithet also refers to the presence of stylets. Armatus (Lat.): armed.

\section{Description}

The only specimen available is $0.5 \mathrm{~mm}$ long, and has two eyes. It is colourless. The proboscis (Fig. 13a: p) is about $20 \%$ of the body length. The pharynx (Fig. 13a: ph) is in the first body half.

The gonads are paired. The testes (Fig. 13a: t) lie at both sides of the body, just behind the pharynx. The ovoid ovaries (Fig. 13a: ov) are situated caudally. Vitellaria were not visible. The gonopore is at ca. $75 \%$.

There are three hard parts in the male atrium: a prostate stylet type II, a prostate stylet type III and an accessory stylet type III. The double-walled prostate stylet type II (Figs 13a: st2, 13b, 14b $_{2}$ ) is $50 \mu \mathrm{m}$ long. It is a simple tube distally, with the proximal rim of the outer stylet very slanting, with one side ending just proximally from the proximal rim of the inner stylet, and the other side extending much further proximally. It is connected to a glandular vesicle (Fig. 13: pv2; prostate vesicle type II?). The prostate stylet type III (Figs 13a: st3, 13d, 14b 3 ) can easily be described using the terminology of Karling (1977), as it is similar to the prostate stylet type III of some species of Austrorhynchus. It is $91 \mu \mathrm{m}$ long, with a proximal style and foot. Distally the foot tapers to a toothed flagellum that ends in a sharp point. The style is proximally split. This prostate stylet is associated with a large glandular organ (Fig. 13a: pv3; pros-
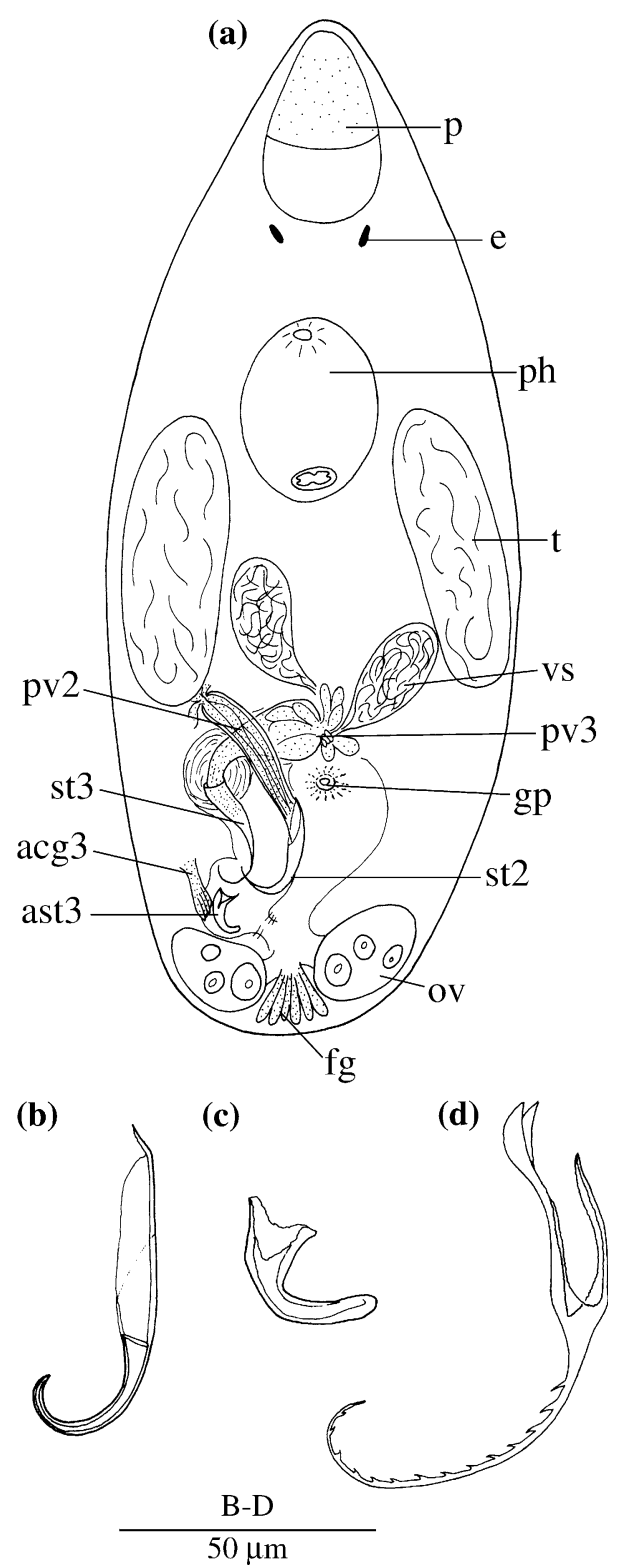

Figure 13. Triaustrorhynchus armatus n. gen., n. sp. (a) General organisation (from a live specimen). (b) Prostate stylet type II (from the holotype). (c) Accessory stylet type III (from the holotype). (d) Prostate stylet type III (from the holotype).

tate vesicle type III?). Where it is connected to the wall of the male atrium, the muscles of the atrium form a thick bulb. The accessory stylet type III (Figs 13a: ast3, 13c, 14b b $_{1}$ is found more distally in the male atrium. It is a hollow, curved tube, $27 \mu \mathrm{m}$ long. It is associated with a small glandular organ (Fig. 13a: acg3; accessory vesicle type III?). There 

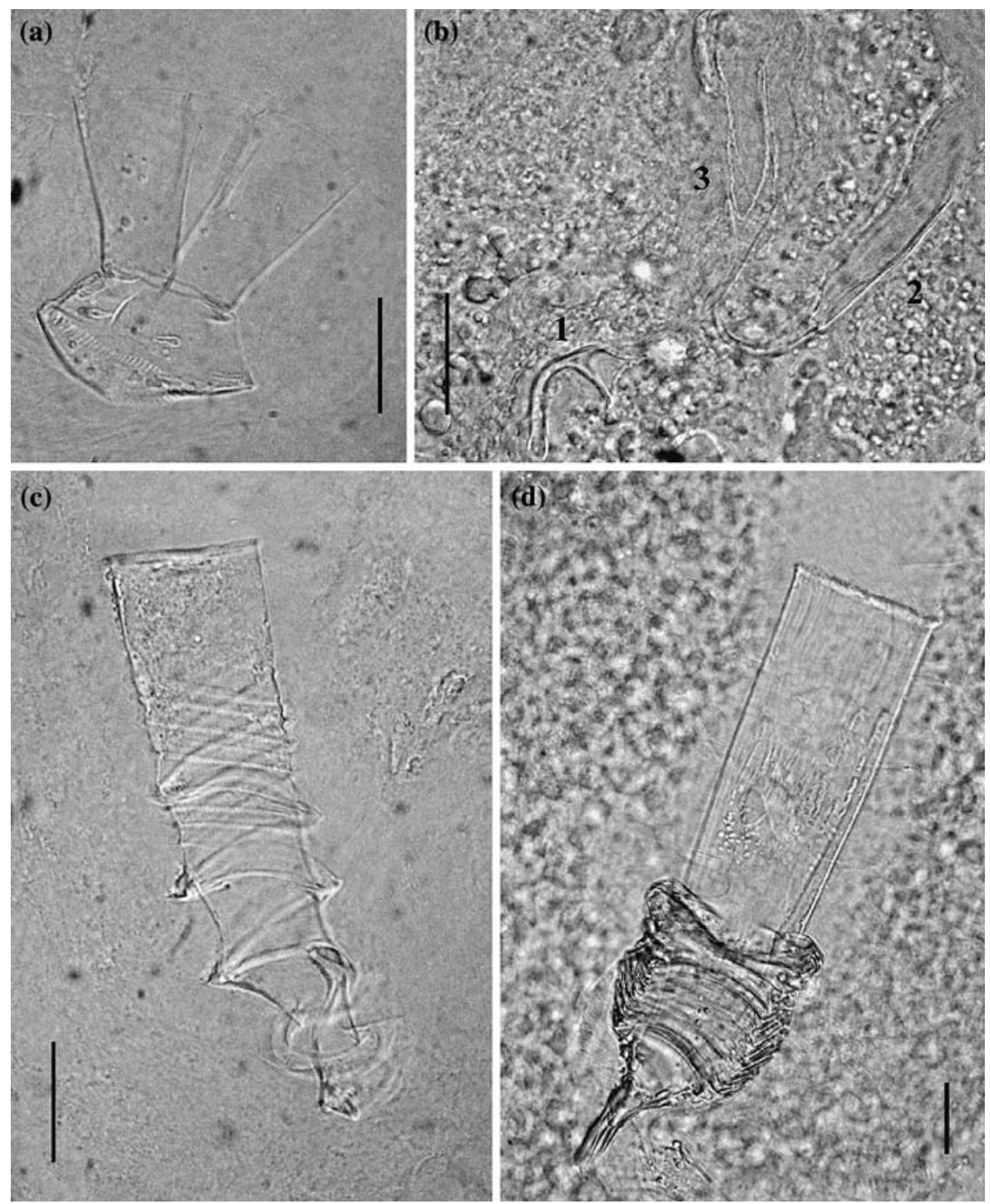

Figure 14. Polycystis australis n. sp. (a) Prostate stylet type I (from the holotype). Triaustrorhynchus armatus n. gen., n. sp. (b) 1. Accessory stylet type III, 2. Prostate stylet type II, 3. Prostate stylet type III (all from the holotype). Stradorhynchus caecus n. gen., n. sp. (c) Single-walled prostate stylet (from the holotype). Stradorhynchus terminalis n. gen., n. sp. (d) Single-walled prostate stylet (from the holotype). Scale bars: $20 \mu \mathrm{m}$.

are two seminal vesicles (Fig. 13a: vs.). The exact course of the ejaculatory duct could not be determined.

At the junction of both oviducts, there is a large bundle of glands (Fig. 13a: fg).

\section{Diagnosis}

Triaustrorhynchus n. gen.: Polycystididae with paired gonads. With three hard parts in the male atrium: a prostate stylet type II connected to a glandular vesicle (prostate vesicle type II?), a prostate stylet type III associated with a large glandular vesicle (prostate vesicle type III?) and an accessory stylet type III associated with a small glandular organ. Type species: T. armatus $\mathrm{n}$. sp.

Triaustrorhynchus terminalis $\mathrm{n}$. $\mathrm{sp}$.: species of Triaustrorhynchus with prostate stylet type II ca. $50 \mu \mathrm{m}$ long, with a wide and asymmetrical opening at the proximal end. Prostate stylet type III ca. 
$91 \mu \mathrm{m}$ long, similar to that of some of the species of Austrorhynchus, with a style and a foot and a distal flagellum. Accessory stylet type III a simple curved tube, ca. $27 \mu \mathrm{m}$ long.

\section{Discussion}

Although sectioned material is lacking, and details of the construction of the anatomy thus cannot be given, the details seen on the live animals combined with the whole mount enable us to describe this species. Because it is the first species of polycystidid with three hard parts in the male system, each of them associated with a glandular organ, we cannot but place it in a genus of its own.

The prostate stylet type II is a short, doublewalled tube, as in many other polycystidids. Most similar is probably the prostate stylet type II of $P$. pacificus, as it also is an evenly curved hook. It is, however, much longer than in T. armatus. Many species of Austrorhynchus also have similar stylets, but in these species it typically has a proximal funnel-shaped part and a tubular distal part, with an abrupt transition between the two parts. Typical for $T$. armatus is the asymmetrical proximal end, which is not found in any other polycystidid with a prostate stylet type II.

The prostate stylet type III is also very similar to that of some species of Austrorhynchus and to a lesser extent to that of the species of Paraustrorhynchus. Moreover, in T. armatus and the species of Austrorhynchus and Paraustrorhynchus a large muscle bulb is associated with this stylet. In $T$. armatus a bundle of glands ends at the base of the prostate stylet type III, at the same place where in species of Paraustrorhynchus a prostate vesicle type III is present. Probably the glandular vesicle observed at this place in T. armatus is a prostate vesicle type III, but this should be checked on sections. It could also be an accessory glandular vesicle of type I, which is also present in the species of Paraustrorhynchus, but is not associated with the prostate stylet type III. Neither of these vesicles is present in the species of Austrorhynchus.

An accessory stylet of type III is very uncommon in polycystidids, and only occurs in $P$. assimilis and species of Antiboreorhynchus Karling, 1952. Only in the species of Antiboreorhynchus is it associated with a compact bundle of accessory glands type III. These glands also occur in P. as- similis, but here they are more diffuse and occur over the whole length of the male atrium. The glands observed in T. armatus are, therefore, most probably comparable to those found in the species of Antiboreorhynchus, but again this should be checked on sections.

The female system of $T$. armatus is one of the most simple within the Polycystididae, and is similar to that of the species of Paraustrorhynchus. It lacks a female bursa, which is present in species of Austrorhynchus and Antiboreorhynhus and in $P$. assimilis.

\section{Acknowledgements}

We wish to thank Mrs Natascha Steffanie for serial sectioning and staining the animals and Dr Sabine Dittmann for kindly providing additional material and drawings of several species, collected during her ecological research. Dr Sven Boström is thanked for lending us the material of $A$. hawaiiensis, present in the collection of the Swedish Museum of Natural History (Stockholm). Dr Nikki Watson is greatly acknowledged for her help during the sampling in Australia, her critical reading of the manuscript and the correction of the English. The first author is supported by a specialisation grant of the Flemish Institute for the Benefit of Scientific and Technological Research in the Industry (IWT-Flanders). The sampling expeditions were supported by grants of the Fund for Scientific Research-Flanders (FWO).

\section{References}

Artois, T. J. \& E. R. Schockaert, 1998. A cladistic re-assessment of the Polycystis species complex (Polycystididae, Eukalyptorhynchia). Hydrobiologia 383: 97-102.

Artois, T. J. \& E. R. Schockaert, 1999. Two new species of the genus Duplacrorhynchus Schockaert \& Karling, 1970, with remarks on relationships within the genus and on the Duplacrorhynchinae (Platyhelminthes, Polycystididae). Belgian Journal of Zoology 129: 235-244.

Artois, T. J. \& E. R. Schockaert, 2003. Primary homology assessment in the male atrial system of the Polycystididae (Platyhelminthes: Eukalyptorhynchia). Zoologischer Anzeiger 242: 179-190.

Artois, T. J. \& E. R. Schockaert, 2005. Primary homology assessment of structures in the female atrial system among species of the Polycystididae (Rhabditophora, Eukalyptorhynchia). Invertebrate Biology 124: 109-118. 
Curini-Galletti, M. C. \& I. Puccinelli, 1990. The Gyratrix hermaphroditus species complex (Platyhelminthes: Kalyptorhynchia) in the Darwin Area (Northern Territory, Australia). Transactions of the American Microscopical Society 109: 368-379.

Curini-Galletti, M. C. \& I. Puccinelli, 1998. The Gyratrix hermaphroditus species complex (Kalyptorhynchia: Polycystididae) in marine habitats of eastern Australia. Hydrobiologia 383: $287-298$.

Dittmann, S., 1991. Plathelminths in tropical intertidal sediments of northeastern Australia. Hydrobiologia 227: 369374

Evdonin, L.A., 1970. A new genus of Turbellarians from the family Polycystididae (Neorhabdocoela). Zoological Journal (Moscow) 49: 781-785. (in Russian).

Evdonin, L. A., 1977. Turbellaria Kalyptorhynchia in the fauna of the USSR and adjacent areas. Fauna USSR 115: 1-400. (in Russian).

Joffe, B. I. \& E. E. Kornakova, 2001. Flatworm phylogeneticist: Between molecular hammer and morphological anvil. In Littlewood, D. T. J. \& R. A. Bray (eds), Interrelationships of the Platyhelminthes. Taylor and Francis, London and New York, 279-291.

Karling, T. G., 1956. Morphologisch-histologische Untersuchungen an den mänlichen Atrialorganen der Kalyptorhynchia (Turbellaria). Arkiv för Zoologi 2: 187-279.

Karling, T. G., 1977. Taxonomy, phylogeny and biogeography of the genus Austrorhynchus (Turbellaria, Kalyptorhynchia). Mikrofauna des Meerenbodens 61: 153-165.

Karling, T. G., 1986. Free-living marine Rhabdocoela (Platyhelminthes) from the N. American Pacific coast. With remarks on species from other areas. Zoologica Scripta 15: 201-219.

Karling, T. G. \& E. R. Schockaert, 1977. Anatomy and systematics of some Polycystididae (Turbellaria, Kalyptorhynchia) from the Pacific and S. Atlantic. Zoologica Scripta 6: 5-19.
Karling, T. G., V. Mack-Fira \& J. Dörjes, 1972. First report on marine microturbellarians from Hawaii. Zoologica Scripta 1: 251-269.

Littlewood, D. T. J. \& P. D. Olson, 2001. Small subunit rDNA and the Platyhelminthes: Signal, noise, conflict and compromise. In Littlewood, D. T. J. \& R. A. Bray (eds), Interrelationships of the Platyhelminthes. Taylor and Francis, London and New York, 262-278.

Littlewood, D. T. J., K. Rohde, R. A. Bray \& E. A. Herniou, 1999. Phylogeny of the Platyhelminthes and the evolution of parasitism. Biological Journal of the Linnean Society 68: 257-287.

Schockaert, E. R., 1982. Turbellaria from Somalia II. Kalyptorhynchia (Part 2). Monitore Zoologico Italiano (N.S.) Suppl. 17: 81-96.

Schockaert, E. R., 1996. The importance of turbellarians in ecosystems. In Hall, G. S. (ed.), Methods for the examination of organismal diversity in soils and sediments. CAB International, Wallingford, 211-225.

Watson, N. A., 2001. Insights from comparative spermatology in the 'turbellarian' Rhabdocoela. In Littlewood, D. T. J. \& R. A. Bray (eds), Interrelationships of the Platyhelminthes. Taylor and Francis, London and New York, 217-230.

Willems, W. R., T. J. Artois, W. A. Vermin, T. Backeljau \& E. R. Schockaert, 2004. Reports on the free-living Platyhelminthes from Australia: Typhloplanoida, with the description of three new taxa. Zoological Science 21: 333-341.

Willems, W. R., T. J. Artois, T. Backeljau \& E. R. Schockaert, 2005. Typhloplanoida (Platyhelminthes, Rhabdocoela) from New Caledonia and eastern Australia, with the description of six new taxa. New Zealand Journal of Zoology 32: 79-98.

Willems, W. R., A. Wallberg, U. Jondelius, D. T. J. Littlewood, T. Backeljau, E. R. Schockaert \& T. J. Artois, 2006. Filling a gap in the phylogeny of flatworms: relationships within the Rhabdocoela (Platyhelminthes), inferred from 18S ribosomal DNA sequences. Zoologica Scripta 35: 1-17. 